\title{
Neutronic feasibility of civil marine small modular reactor core using mixed $\mathrm{D}_{2} \mathrm{O}+\mathrm{H}_{2} \mathrm{O}$ coolant
}

\author{
Syed Bahauddin Alam ${ }^{\mathrm{a}, *}$, Bader Almutairi ${ }^{\mathrm{d}}$, Dinesh Kumar ${ }^{\mathrm{c}}$, Safwan Jaradat ${ }^{\mathrm{f}}$, Cameron S. \\ Goodwin $^{\mathrm{b}}$, Kirk D. Atkinson ${ }^{\mathrm{e}}$, Geoffrey T. Parks ${ }^{\mathrm{a}}$ \\ ${ }^{a}$ Department of Engineering, Cambridge University, Cambridge, CB2 1PZ, United Kingdom \\ ${ }^{b}$ Rhode Island Atomic Energy Commission, Narragansett, Rhode Island, USA \\ ${ }^{c}$ Physics and Astronomy Department, Uppsala University, Sweden \\ ${ }^{d}$ Department of Mining and Nuclear Engineering, Missouri S\&T, USA \\ ${ }^{e}$ University of Ontario Institute of Technology, Oshawa, Ontario, Canada \\ ${ }^{f}$ Higher Colleges of Technology, Abu Dhabi, United Arab Emirates
}

\begin{abstract}
In an effort to decarbonize the marine sector, there are growing interests in replacing the contemporary, traditional propulsion systems with nuclear propulsion systems. The latter system allows freight ships to have longer intervals before refueling; subsequently, lower fuel costs, and minimal carbon emissions. Nonetheless, nuclear propulsion systems have remained largely confined to military vessels. It is highly desirable that a civil marine core not to use highly enriched uranium, but it is then a challenge to achieve long core lifetime while maintaining reactivity control and acceptable power distributions in the core. The objective of this study is to design a civil marine core type of single batch small modular reactor (SMR) with low enriched uranium (LEU) $\left(<20 \%{ }^{235} \mathrm{U}\right.$ enrichment), a soluble-boron-free (SBF) and using mixed $\mathrm{D}_{2} \mathrm{O}+\mathrm{H}_{2} \mathrm{O}$ coolant for operation period over a 20 years life at 333 MWth. Changing the coolant properties is the way to alter the neutron energy spectrum in order to achieve a self-sustaining core design of higher burnup. Two types of LEU fuels were used in this study: micro-heterogeneous $\mathrm{ThO}_{2}-\mathrm{UO}_{2}$ duplex fuel $\left(18 \%{ }^{235} \mathrm{U}\right.$ enriched) and all- $\mathrm{UO}_{2}$ fuel $\left(15 \%{ }^{235} \mathrm{U}\right.$ enriched). 2D Assembly designs are developed using WIMS and 3D whole-core model is developed using PANTHER code. The duplex option shows greater promise in the final burnable poison design with high thickness $\mathrm{ZrB}_{2}$ integral fuel burnable absorber (IFBA) while maintaining low, stable reactivity with minimal burnup penalty. For the final poison design with $\mathrm{ZrB}_{2}$, the duplex contributes $\sim 2.5 \%$ more initial
\end{abstract}


reactivity suppression, although the all- $\mathrm{UO}_{2}$ design exhibits lower reactivity swing. Three types of candidate control rod materials: hafnium, boron carbide $\left(\mathrm{B}_{4} \mathrm{C}\right)$ and $80 \%$ silver $+15 \%$ indium $+5 \%$ cadmium $(\mathrm{Ag}-\mathrm{In}-\mathrm{Cd})$ are examined and duplex fuel exhibits higher control rod worth with the candidate materials. $\mathrm{B}_{4} \mathrm{C}$ shows the greatest control reactivity worth for both the candidate fuels, providing $\sim 3 \%$ higher control rod worth for duplex fuel than all- $\mathrm{UO}_{2}$. Finally, 3D whole-core results from PANTHER show that the use of the mixed coolant contributes to $\sim 21.5$ years core life, which is a $\sim 40 \%$ increase in core life compared to $\mathrm{H}_{2} \mathrm{O}$ coolant $(\sim 15.5$ years $)$ while using the same fuel candidates and fissile enrichment. The mixed coolant provides excellent core lifetimes comparable to those of HEU military naval vessels ( $\sim 25$ years vs. $\sim 21.5$ years $)$ while utilizing LEU candidate fuels.

\section{Abbreviations}

2 BOL Beginning-of-life

3 BP Burnable poisons

$4 \quad$ BPZ Burnable poison zoning

5 CXS Capture cross section

6 CZP Cold zero power

7 (D)H/HM Deuterium+hydrogen-to-heavy-metal ratio

8 DPC Doppler power coefficient

9 Duplex fuel Micro-heterogeneous $\mathrm{ThO}_{2}-\mathrm{UO}_{2}$

FTC Fuel temperature coefficient

11 HFP Hot full power

\footnotetext{
*Corresponding author

Email address: syed.nuclear@cantab.net (Syed Bahauddin Alam)
} 
H/HM Hydrogen-to-heavy-metal ratio

HZP Hot zero power

IFBA Integral fuel burnable absorber

80\% $\mathrm{D}_{2} \mathrm{O}+\mathbf{2 0 \%} \mathrm{H}_{2} \mathrm{O}$ Mixed coolant

MTC Moderator temperature coefficient

RCCA Rod cluster control assembly worth

SBF Soluble-boron-free

SMR Small Modular Reactor

\section{Introduction}

In recent decades, there have been excessive carbon dioxide emissions due to the evergrowing global population. This growth comes naturally with an increasing demand for energy. Most of the energy produced these days come from hydrocarbon-based fuels that contribute devastatingly to climate change. With the world economys flourishing, international trading between countries has been growing progressively as well. International trading has been identified as one of the leading factors that are driving the worlds economy within which seaborne trade takes a large share. At present, $99 \%$ of the total freight commercial shipping is driven by low to medium speed diesel engines in which they are responsible for a total of $3 \%$ of worldwide carbon dioxide emission (Hirdaris et al., 2014, Ragheb, 2012). Though alternative fuels are being considered including solar, biofuels and wind, none of these is particularly promising in the context of $80 \%$ reduction in carbon emission by 2050 , which is the target for many developed countries. Nuclear power has the ability to fill this gap in energy technology (Hirdaris et al., 2014, Ragheb, 2012). Nuclear power contributes no $\mathrm{CO}_{2}$ emission; henceforth, nuclear energy is recognized as clean energy. Nuclear power has been into existence for peaceful applications for over 60 years. Apart from nuclear power stations, 
nuclear power is also used for shipping propulsion-while mainly for military purposes. Nuclear propulsion research that was launched by the United States in the early 1940s motivated the development of Pressurized Water Reactor (PWR) (Hirdaris et al., 2014, Ragheb, 2012, Alam, 2018). In the early 50s, the development of naval nuclear propulsion resulted in the lunch of the USS Nautilus in 1955. Since then, nuclear-powered ships had been without any major accidents. This fact demonstrates that nuclear marine propulsion is a reliable-safe choice (Ragheb, 2012, Alam, 2018).

There are about 140 nuclear-powered ships with the vast majority of these being military vessels: submarines, aircraft carriers or cruisers (Ragheb, 2012). Few civil or commercial ships have been equipped with nuclear propulsion. Most importantly, apart from the significant environmental benefits, nuclear propulsion exhibits marked stability in the face of volatile fuel prices because of its unique price structure. According to the US Nuclear Energy Institute, nuclear fuel only accounts for $\sim 14 \%$ of the total costs of nuclear energy (Otto, 2013); as a result, changes in the price of primary resources have little effect on operating costs. In contrast, fossil fuel prices have historically experienced dramatic fluctuations: for instance, the price of heavy fuel oil nearly tripled between January 2007 and July 2008 (Otto, 2013, Namikawa et al., 2011). It is, therefore, a detailed design of advanced nuclear technology that is cost-effective will result in a superior nuclear propulsion system than the current utilized conventional propulsion systems (Otto, 2013, Namikawa et al., 2011). The key economic advantage of a nuclear-powered container ship is that it can practically double its yearly revenue compared to a conventional fossil-fueled vessel (Hass, 2014, Otto, 2013, Namikawa et al., 2011). Nonetheless, nuclear power has not been widely applied to shipping for several key reasons: (1) Almost all the experience with marine reactors has been with highly enriched uranium. Civil shipping reactors will require a low enriched core design, which also has a long operating lifetime; (2) The need for an international infrastructure to operate, maintain and support such reactors with its attendant cost; (3) Nuclear licensing and regulation has national variations. Harmonization of nuclear regulations or the mutual recognition of different licensing standards would be required for the significant application of nuclear power to shipping. The solutions to the aforementioned technical issues are hindered by the 
demands of the aboard environment that results in the following: the limitation of space and weight; rolling and pitching issues; and safety and shielding concerns (Kramer, 1962). These challenges can be potentially solved by a promising design of PWR-small modular reactors (SMR) (Alam et al., 2019d,g,f,c).

One of the main reactor core design challenges is to develop an efficient reactivity control system (Alam et al., 2019d,g). Generally, traditional PWRs use a combination of three methods of reactivity control: moveable control rods, burnable neutron absorbers, and soluble neutron absorbers. PWRs use soluble boron for uniform power suppression throughout the core by suppressing excess reactivity. There are, however, several benefits for the elimination of soluble boron from reactors such as improved safety; simplification of the overall reactor design by reducing the purification systems with their related components; space reduction; and elimination of the degradation effects of soluble boron on the reactor components. A fundamental strategy of designing a reactor core to be soluble-boron-free (SBF) is the increasing dependence on control rods and burnable poisons (BPs) which both are local neutron absorbers. During regular operation, control rods are inserted in a calculated manner in order to control the reactor power; however, their presence distorts the axial power profile negatively. This, in turn, results in undesirable power peaks and consequently, there is a reduced operating margin which ultimately leads to a significant economic loss. The main challenge in designing any SBF reactor is, therefore, to minimize power peaks while maintaining a proper axial power profile. Besides, relying strongly on moveable control rods would add complexity to the reactors control system. It will also elevate the risk of having rod-associated accidents. Hence, BPs perform a significant role in the reactivity control scheme of our SBF civil marine core design.

To date, a limited number of studies (Tochihara et al., 1998, Engelder, 1961) have been conducted for "mixed coolant" $\left(\mathrm{H}_{2} \mathrm{O}+\mathrm{D}_{2} \mathrm{O}\right)$, although it has never been practically employed (Nagy et al., 2014). Also, the 2003 MIT studies (Xu, 2003, Xu and Driscoll, 1997) observed the achievable burnup and initial reactivity behavior of PWR lattice over hydrogen-to-heavymetal ratio $(\mathrm{H} / \mathrm{HM})$ for the $\mathrm{H}_{2} \mathrm{O}$ coolant. However, these studies (Tochihara et al., 1998, Nagy et al., 2014, Xu, 2003, Xu and Driscoll, 1997, Engelder, 1961) are limited to lower fissile 
enrichment (5\%) and soluble boron system. Furthermore, for SBF SMR cores, there have not been many studies conducted to understand the reactor physics behavior of the mixed coolant $\left(\mathrm{D}_{2} \mathrm{O}+\mathrm{H}_{2} \mathrm{O}\right)$ (Alam, 2018, Otto, 2013, Ippolito, 1990). In order to fill this potential gap, we have considered a mixture of $80 \% \mathrm{D}_{2} \mathrm{O}+20 \% \mathrm{H}_{2} \mathrm{O}$ as a coolant since $\mathrm{D}_{2} \mathrm{O}$ exhibits the smaller neutron absorption than that of the traditional $\mathrm{H}_{2} \mathrm{O}$ coolant and therefore, offers the potential of longer core lifetime. It has been observed from our previous lattice optimization/parametric studies (Alam et al., 2019c) that the mixed $\mathrm{D}_{2} \mathrm{O}+\mathrm{H}_{2} \mathrm{O}$ coolant ${ }^{1}$ exhibits the superior performance compared to the $\mathrm{H}_{2} \mathrm{O}$ in terms of discharge burnup in a specific moderation regime $((\mathrm{D}) \mathrm{H} / \mathrm{HM}=\sim 2$ to $\sim 6)$. Since the (D)H/HM value of our proposed core lies within this value $\left(\mathrm{H} / \mathrm{HM}=3.99\right.$ and $\left.\mathrm{DH} / \mathrm{HM}^{2}=5.0\right), \mathrm{D}_{2} \mathrm{O}+\mathrm{H}_{2} \mathrm{O}$ exhibits to be the potential coolant candidate for improving the core lifetime of the proposed SBF, SMR core (Alam et al., 2019d,g). Therefore, it is worthwhile to examine the neutronic feasibility of the mixed coolant for the proposed SMR core. The objective of this study is to observe the neutronic feasibility of assembly-level and whole-core studies for the mixture of $80 \%$ $\mathrm{D}_{2} \mathrm{O}+20 \% \mathrm{H}_{2} \mathrm{O}$ coolant and considered the design of burnable poisons (BPs), control rods and whole-core feasibility for the proposed 333 MWth SMR marine core with two types of candidate fuels: all- $\mathrm{UO}_{2}$ and micro-heterogenous $\mathrm{ThO}_{2}-\mathrm{UO}_{2}$ duplex with $15 \%$ and $18 \%{ }^{235} \mathrm{U}$ fissile enrichment, respectively, and loaded into $13 \times 13$ assemblies (Alam et al., 2019f,c, Zhao, 2001, MacDonald and Lee, 2004) for the single batch operation.

The main motivations and objectives behind this study can be addressed as following:

1. According to our SMR core design study (Alam et al., 2019g) with $\mathrm{H}_{2} \mathrm{O}$ coolant, proposed SMR core obtained a maximum lifetime of $\sim 15.53$ years. Therefore, the main motivation of this study is to obtain core lifetimes comparable to those of high-enriched uranium (HEU) military naval vessels ( $\sim 20-25$ years) while utilizing LEU fuels with the mixed coolant.

2. Whole-core study is limited to feasibility analysis and to confirm whether the use of mixed coolant can offer $\sim 20$ years core life. Since "optimization study" is out of

\footnotetext{
${ }^{1}$ This paper refers to $80 \% \mathrm{D}_{2} \mathrm{O}+20 \% \mathrm{H}_{2} \mathrm{O}$ and $\mathrm{D}_{2} \mathrm{O}+\mathrm{H}_{2} \mathrm{O}$ interchangeably as "mixed coolant".

2 "DH/HM" refers to deuterium+hydrogen-to-heavy-metal ratio.
} 
the scope of this paper and the main objective of this study is to obtain maximum attainable lifetime for the proposed SMR core with the mixed coolant and therefore, we consider relaxed through-life "reactivity swing" condition for the whole-core design studies. The scope of this whole-core neutronic feasibility is limited to evaluate and understand the core life while observing reactivity feedback values over the core life.

3. To use of the mixed coolant contributes to ultra-long life at the expense of higher through-life reactivity swings of $\sim 6,000$ pcm than that of the $\mathrm{H}_{2} \mathrm{O}$ coolant.

4. This study will specifically observe the performance of burnable poisons (BPs) and control rods with the mixed coolant in the lattice-level since no study has been performed to date on duplex fuel and mixed coolant in the SBF SMR environment.

The scope of this study is confined to the design methods, determination of fissile inventory loading and coolant molecular ratios, and reactivity control (lattice-level) and whole-core feasibility (limited to core lifetime and reactivity feedback values). The safety issues such as thermal-hydraulics and fuel performance are out of the scope of this paper.

\section{Design and Computational Methods}

Preliminary sizing calculations for the required fuel mass, core height/diameter ratio, core volume and dimensions, fuel diameter and assembly size are performed in (Alam, 2018), as shown in Fig. 1. Derived from the previous studies (Alam et al., 2019d,g), this study considers 112 assemblies with a $13 \times 13$ pin array design for the proposed SMR core design (Fig. 2a).

This study considers the deterministic reactor physics code WIMS 10 (Newton et al., 2008) for the lattice-level calculation while considering JEF 2.2 nuclear data library and 6 energy group structure, consistent with our previous studies (Alam et al., 2019a,d,g,e,f,c,b). WIMS performs deterministic neutron transport calculations for every pin in a fuel assembly using an established calculation route through sequence of separate modules (Newton et al., 2008, Alam et al., 2019a,e). Since WIMS performs 2D lattice calculation assuming an infinitely large core, this code is unable to assess neutron leakage. Therefore, 3D FORTRAN-based advanced 


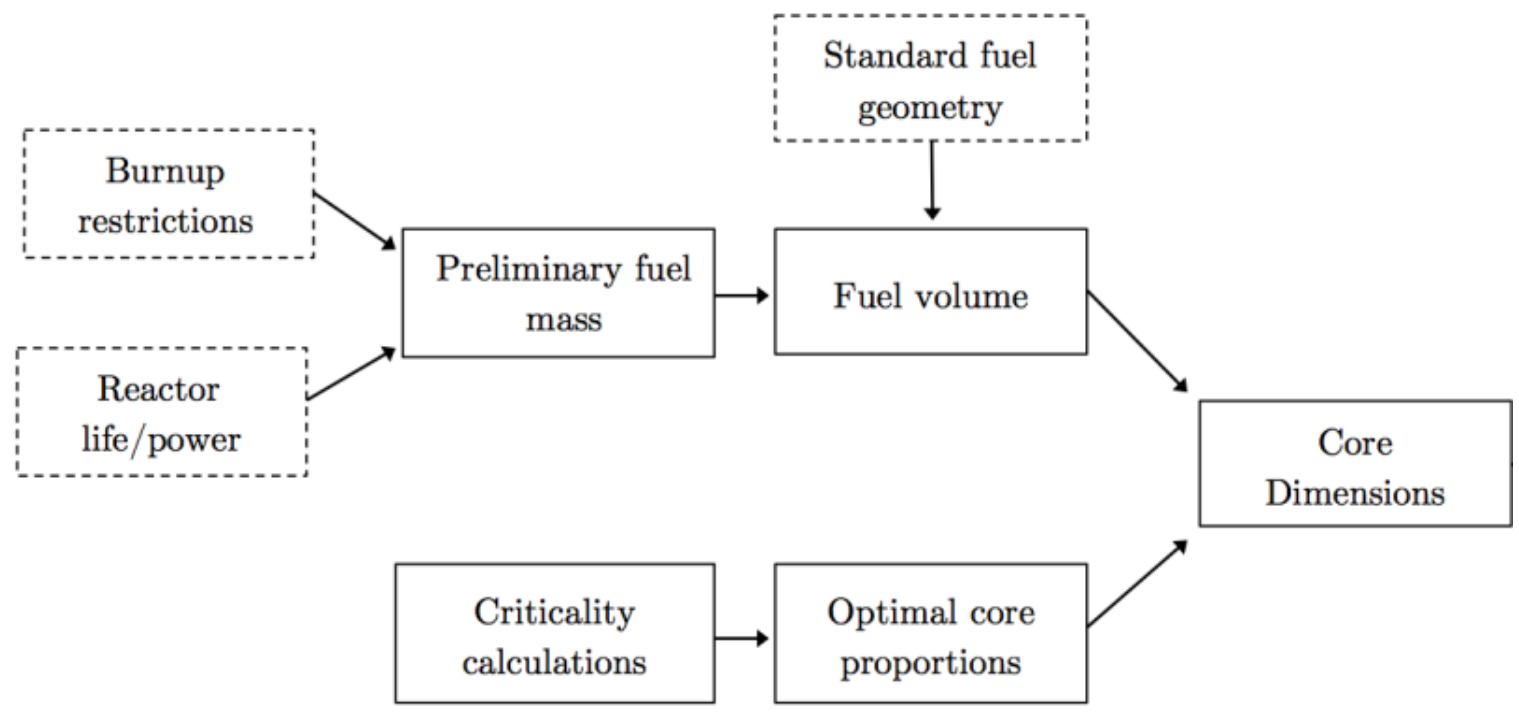

Fig. 1. Preliminary design procedure. (Otto, 2013, Fan, 2012, Sun, 2014, Zhang, 2013, Alam, 2018).

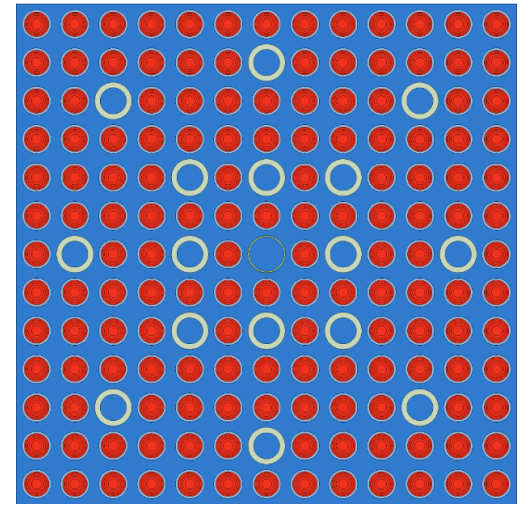

(a)

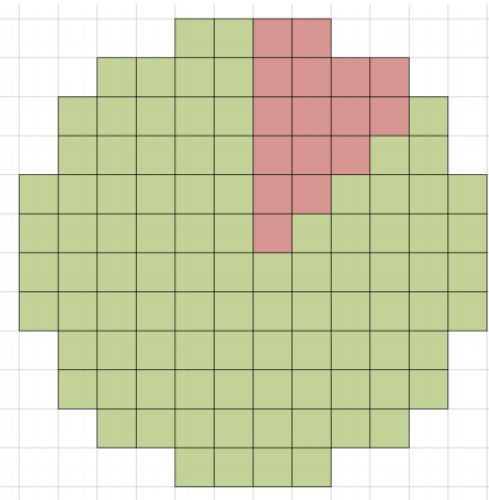

(b)

Fig. 2. Assembly sizing (Alam et al., 2019d, Alam, 2018): (a) $13 \times 13$ pin array assembly design; (b) Core schematic of a 112-assembly. 
3D nodal code PANTHER (Hutt, 1992) is used in this study for whole-core modeling and analyses. For the sake of brevity, a detailed working principle of WIMS/PANTHER isn't provided and the detailed description and operations of WIMS and PANTHER are provided in our previous studies (Alam et al., 2019a,e,f, Alam, 2018).

This study considers $15 \%{ }^{235} \mathrm{U}$ enriched all- $\mathrm{UO}_{2}$ fuel and $18 \%{ }^{235} \mathrm{U}$ enriched duplex fuel (Fig. 3) in a $13 \times 13$ assembly while assuming $7.5 \%$ neutron leakage and discharge burnup limit of $100 \mathrm{GWd}$ /tonne in the WIMS model (Alam et al., 2019e). The fissile loading has been determined through parametric enrichment calculations for the candidate fuels, as shown in Fig. 5. The detailed computational and design methods are reported in our previous studies (Alam et al., 2019d,g,e,f,c,b,a). Table 1 shows the 2D lattice-level (WIMS) and 3D whole-core (PANTHER) system parameter values.

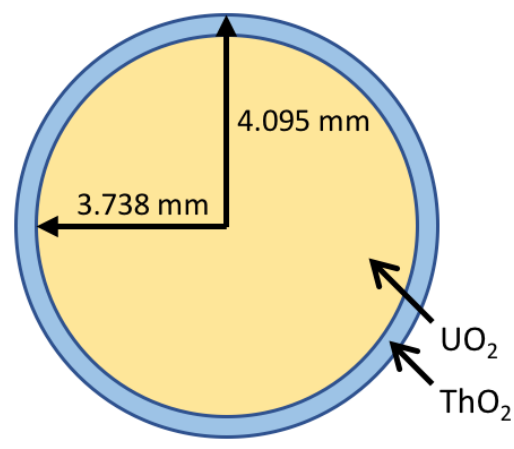

Fig. 3. Micro-heterogeneous duplex fuel configuration (Alam et al., 2019d,g,e,f,c,b).

\subsection{Coolant Molecular Ratios}

Light $\mathrm{H}_{2} \mathrm{O}$ and heavy $\mathrm{D}_{2} \mathrm{O}$ water are mixed together ranging from $0-100 \% \mathrm{D}_{2} \mathrm{O}$ to be used as a coolant for both candidate fuels. At the range of $80 \% \mathrm{D}_{2} \mathrm{O}+20 \% \mathrm{H}_{2} \mathrm{O}$, the candidate fuels achieve the maximum discharge rates as shown in Figs. 5a and 5b. The highest uranium utilization can be reached at the range more than $80 \% \mathrm{D}_{2} \mathrm{O}$, where the reduced presence of hydrogen atoms leads to a significant reduction in the thermal neutron utilization leads to dominant neutron capture in the mixed coolant. The range of $80 \% \mathrm{D}_{2} \mathrm{O}+20 \% \mathrm{H}_{2} \mathrm{O}$ of the mixed coolant is taken as the optimum selection in this study. Table 1 shows the main characteristics of the proposed SMR marine core reactor (Alam, 2018). 


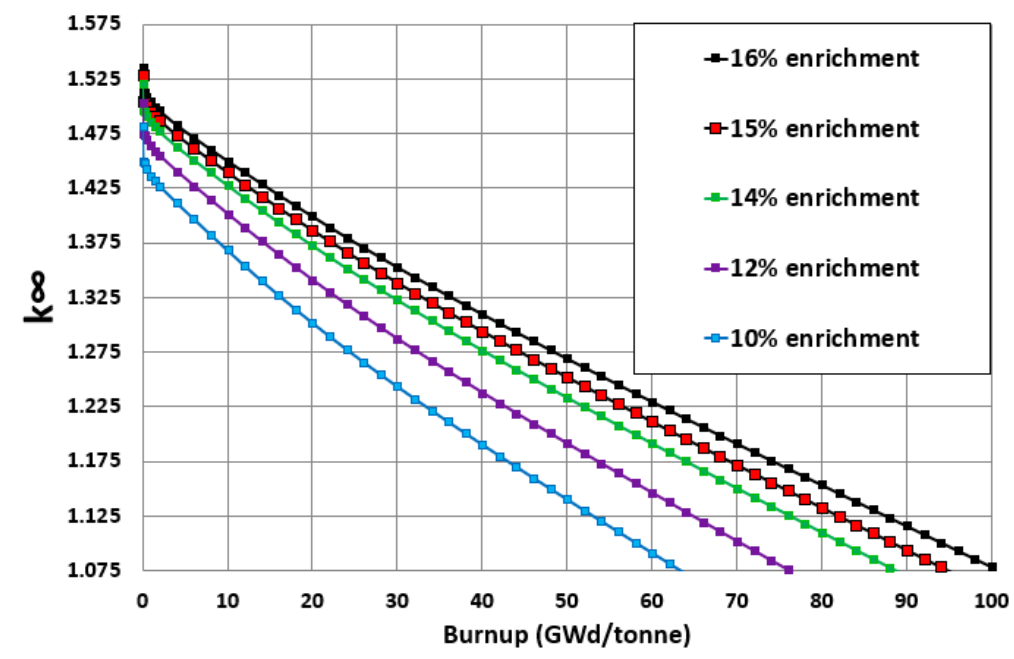

(a)

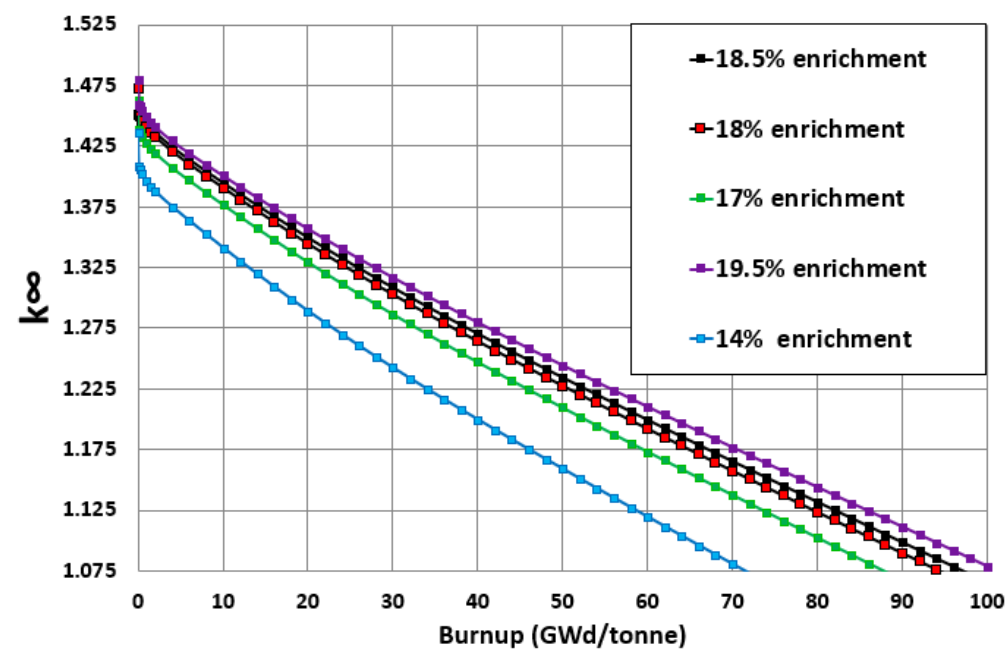

(b)

Fig. 4. Fissile loading determination: (Alam et al., 2019d,g,e,f,c,b): (a) $\mathrm{UO}_{2}$; (b) Duplex. 


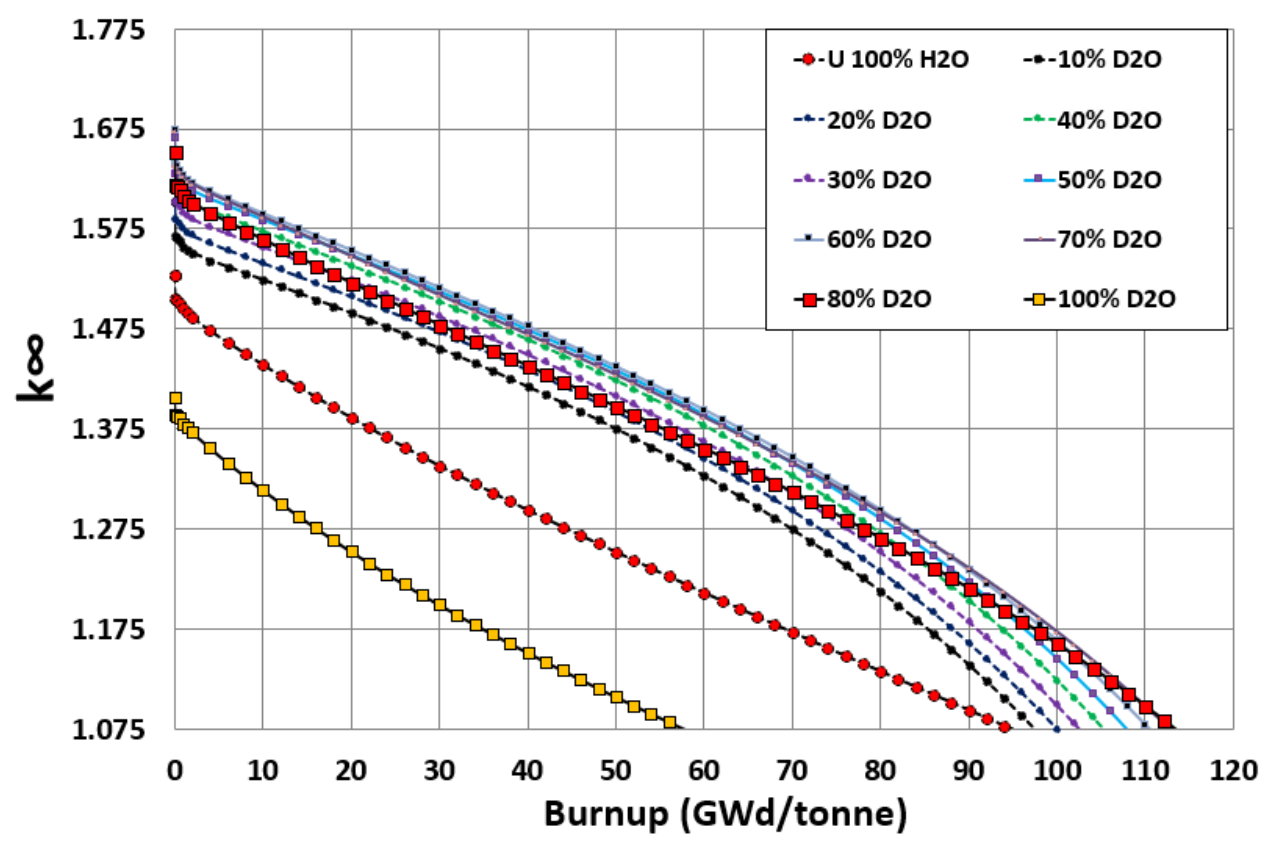

(a)

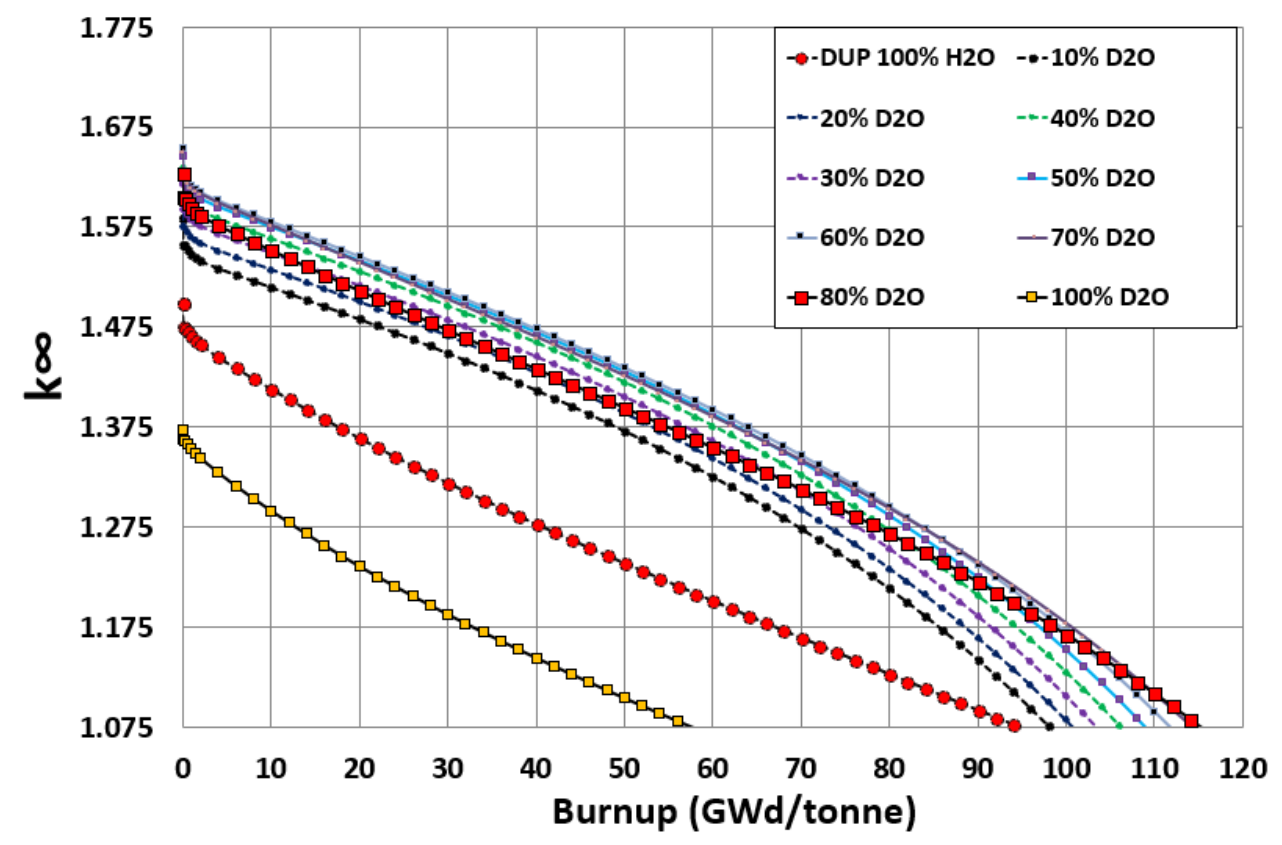

(b)

Fig. 5. Fuel burnup calculations for the mixtures of $\mathrm{H}_{2} \mathrm{O}-\mathrm{D}_{2} \mathrm{O}$ water at varying ranging (Alam et al., 2019c): (a) $15 \%{ }^{235} \mathrm{U}$ enriched all- $\mathrm{UO}_{2}$ fuel; (b) $18 \%{ }^{235} \mathrm{U}$ enriched duplex fuel. 


\begin{tabular}{|c|c|c|c|}
\hline Plant properties & Value & Fuel geometry & Value \\
\hline Desired electrical power (MWe) & 100 & Gap thickness (mm) & 0.05 \\
\hline Thermal efficiency (\%) & 30 & Cladding thickness (mm) & 0.61 \\
\hline Thermal output power (MWth) & 333 & Cladding + gap thickness $(\mathrm{mm})$ & 0.66 \\
\hline Minimum desired lifetime (years) & 20 & Pellet diameter (mm) & 8.19 \\
\hline Availability & 1.00 & Total rod diameter (mm) & 9.5 \\
\hline Assembly properties & Value & Whole-core attributes & Value \\
\hline Assembly size & $13 \times 13$ & Diameter $(\mathrm{m})$ & 1.97 \\
\hline Control rods per assembly & 16 & Fuel height (m) & 1.79 \\
\hline Centre-to-centre pitch $(\mathrm{cm})$ & 1.26 & Volume $\left(\mathrm{m}^{3}\right)$ & 5.4 \\
\hline $\mathrm{H} / \mathrm{HM}$ ratio & 3.99 & Inlet temperature $\left({ }^{\circ} \mathrm{C}\right)$ & 295.6 \\
\hline $\mathrm{DH} / \mathrm{HM}$ ratio & 5.0 & Total fuel volume $\left(\mathrm{m}^{3}\right)$ & 1.65 \\
\hline \multirow[t]{13}{*}{ Pitch/diameter ratio } & 1.33 & Heavy metal mass (tonne) & 18.23 \\
\hline & & Coolant pressure (MPa) & 15.5 \\
\hline & & Soluble boron concentration (ppm) & 0 \\
\hline & & Total coolant flow rate $(\mathrm{kg} / \mathrm{s})$ & 8370.2 \\
\hline & & Number of reactor channels & 164 \\
\hline & & Number of core channels & 112 \\
\hline & & Number of channel columns & 14 \\
\hline & & Number of channel rows & 14 \\
\hline & & Number of core axial layers & 16 \\
\hline & & Number of reactor axial layers & 18 \\
\hline & & Number of radial reflector channels & 52 \\
\hline & & Power density within core $\left(\mathrm{MW} / \mathrm{m}^{3}\right)$ & 63 \\
\hline & & Average linear rating $(\mathrm{kW} / \mathrm{m})$ & 10 \\
\hline
\end{tabular}

Table 1. System parameter values for the proposed SMR marine core. 


\section{Burnable Poison Design for the Mixed Coolant}

Since $\mathrm{D}_{2} \mathrm{O}$ has a small neutron capture cross section (CXS) compared to the $\mathrm{H}_{2} \mathrm{O}$, it increases the beginning-of-life (BOL) reactivity of the core. Therefore, it is expected that the use of mixed coolant requires us to use a higher number of $\mathrm{BP}$ pins compared to the $\mathrm{H}_{2} \mathrm{O}$ coolant to suppress the higher BOL reactivity. This is due to the fact that, within the under-moderated region, the mixed coolant has a higher peak $k_{\infty}$ than the $\mathrm{H}_{2} \mathrm{O}$ coolant by $\sim 2 \%$ for both candidate fuels, as shown in Figs. 6 a and 6 b.

Therefore, it is expected that higher BP loading and thickness will be required to suppress this higher reactivity caused by the mixed coolant. According to our previous studies (Alam et al., 2019d, 2015, Alam, 2018), ZrB $_{2}$ high thickness integral fuel burnable absorber (IFBA) exhibits superior BP performance compared to the traditional BP options: $\mathrm{Gd}_{2} \mathrm{O}_{3}$ and $\mathrm{Er}_{2} \mathrm{O}_{3}$. Therefore, in this study, the assembly will use IFBA poison with mixed coolant.

\subsection{High-Thickness IFBA Coating}

In this study, 29 to 45 IFBA rods designs adapted for the duplex and all- $\mathrm{U}_{2}$ fuels have been considered in our assembly. For the sake of efficiently suppress the higher reactivity ensuing from the mixed coolant as well as to achieve the crucial self-shielding effects; a high-thickness $150 \mu \mathrm{m} \mathrm{ZrB}_{2}$ coating has been considered as a reference from our previous study (Alam et al., 2019d) and is used throughout our IFBA designs. Boron $\left(95 \%{ }^{10} \mathrm{~B}\right)$ is considered as black absorber because of its high CXS section of neutrons with absorption- tototal XS ratio $\sigma_{a} / \sigma_{t}=0.95$. The rationale of using thick coating IFBA (up to $250 \mu \mathrm{m}$ ) for the long core-life application is provided in our previous studies (Alam et al., 2019d, Alam, 2018)

It can be observed in Figs. 7a and 7b that as expected, for the mixed coolant, initial reactivity suppression is almost linearly proportional to the number of IFBA pins for both the candidate fuels. However, similar to the $\mathrm{H}_{2} \mathrm{O}$ coolant study (Alam et al., 2019d), we observe almost no residual burnup penalty for IFBA designs.

Various numbers of IFBA pins were considered for both fuels with $150 \mu \mathrm{m}$ coatings in order to compare the performance of initial reactivity suppression as well as the reactivity 


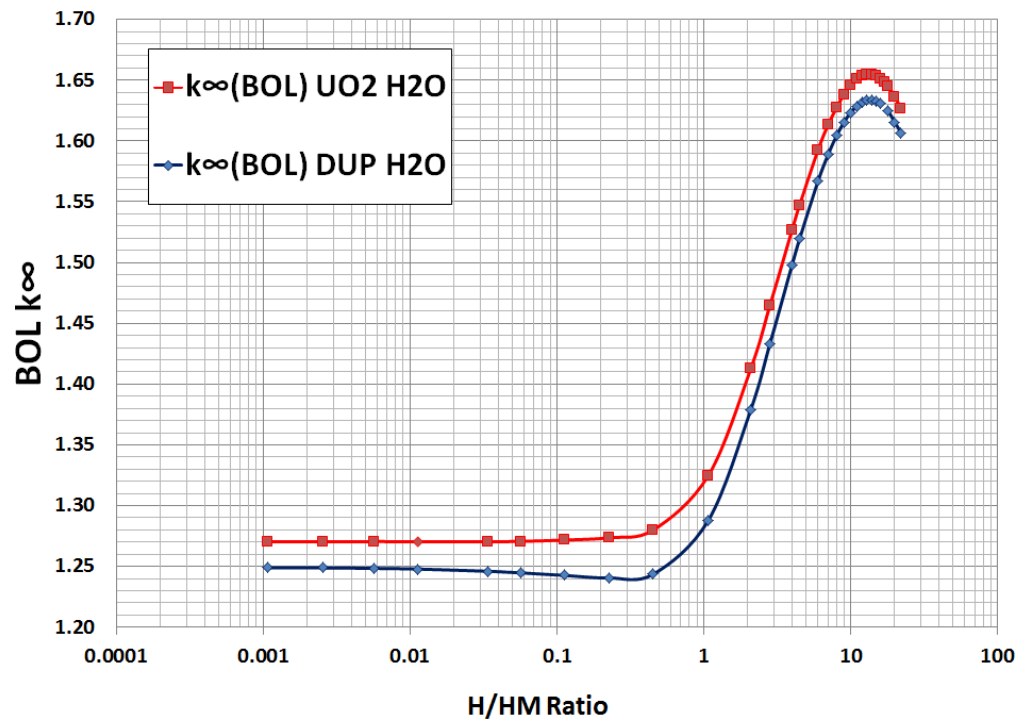

(a)

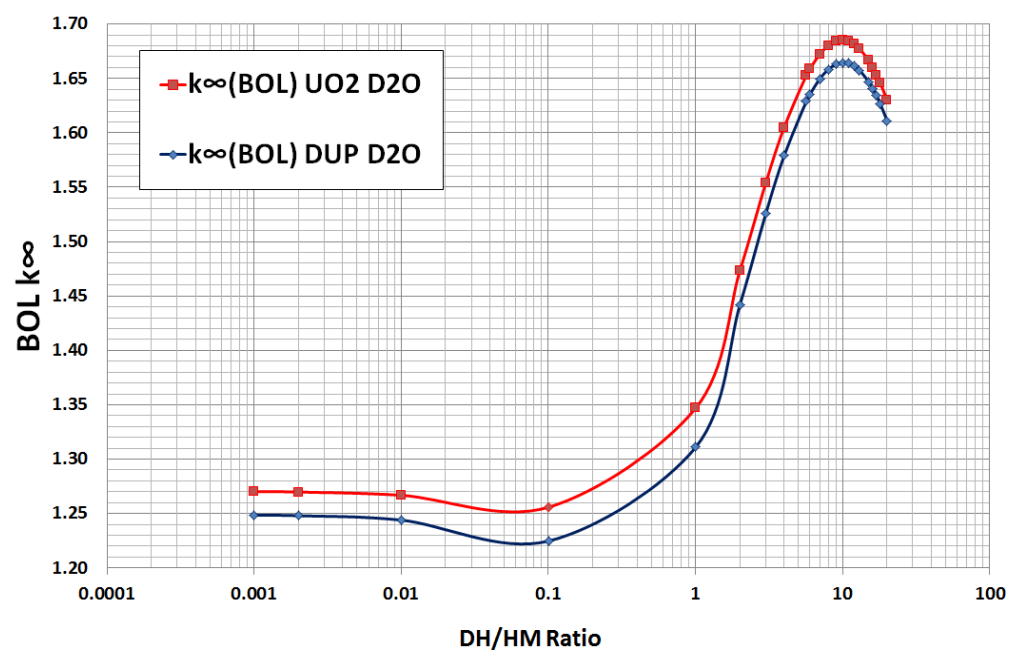

(b)

Fig. 6. (a) H/HM vs. $k_{\infty}$ at BOL (Alam et al., 2019c) (b) DH/HM vs. $k_{\infty}$ at BOL (Alam et al., 2019c). 


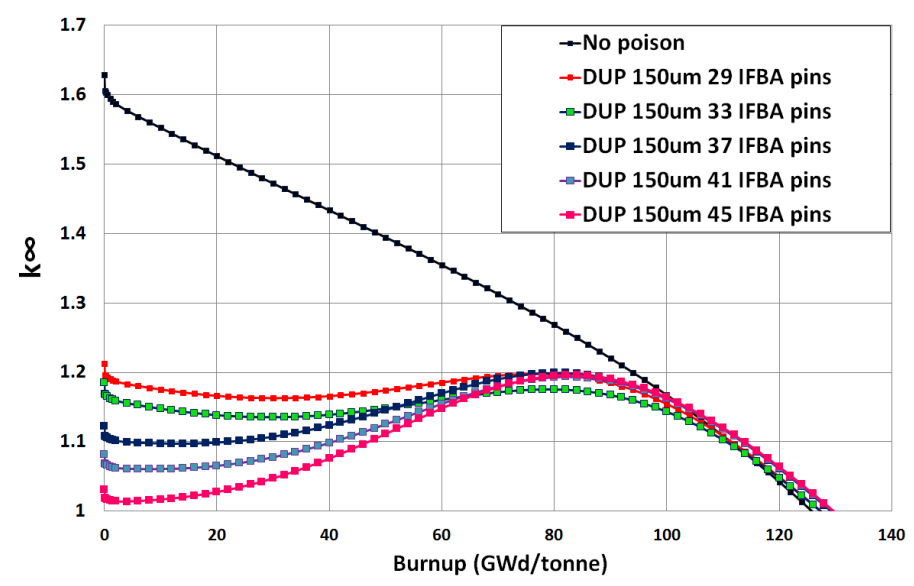

(a)

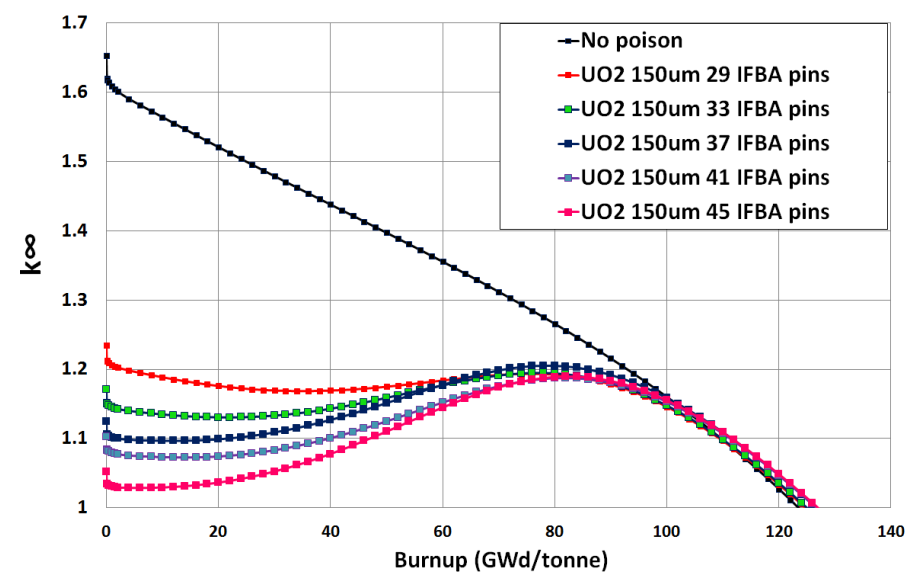

(b)

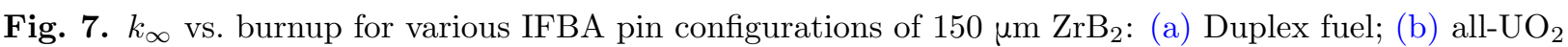
fuel. 
swing. The reactivity swing results are mixed depending on the thickness and loading. It is clear from Figs. 8 and 9 that the all- $\mathrm{UO}_{2}$ fuel exhibits larger (by $\sim 5 \%$ ) swings than the duplex fuel for BP loadings with less than 37 IFBA pins during the burnup time. Duplex fuel has a smaller reactivity swing because of the production of new fissile material $\left({ }^{233} \mathrm{U}\right.$ in duplex fuel vs. ${ }^{239} \mathrm{Pu}$ in all- $\mathrm{UO}_{2}$ fuel) which leads to reduce the fissile content more slowly during the discharge burnup. On the other hand, with BP loadings greater than 37 IFBA pins, the duplex fuel exhibits worse reactivity swing performance than $\mathrm{UO}_{2}$. Due to the effectiveness of the $150 \mu \mathrm{m}$ IFBA coating in absorbing neutrons, the beneficial build-up of ${ }^{233} \mathrm{U}$ is delayed ( as a result of very high-thickness BP coating) in comparison to the lower IFBA loading cases.

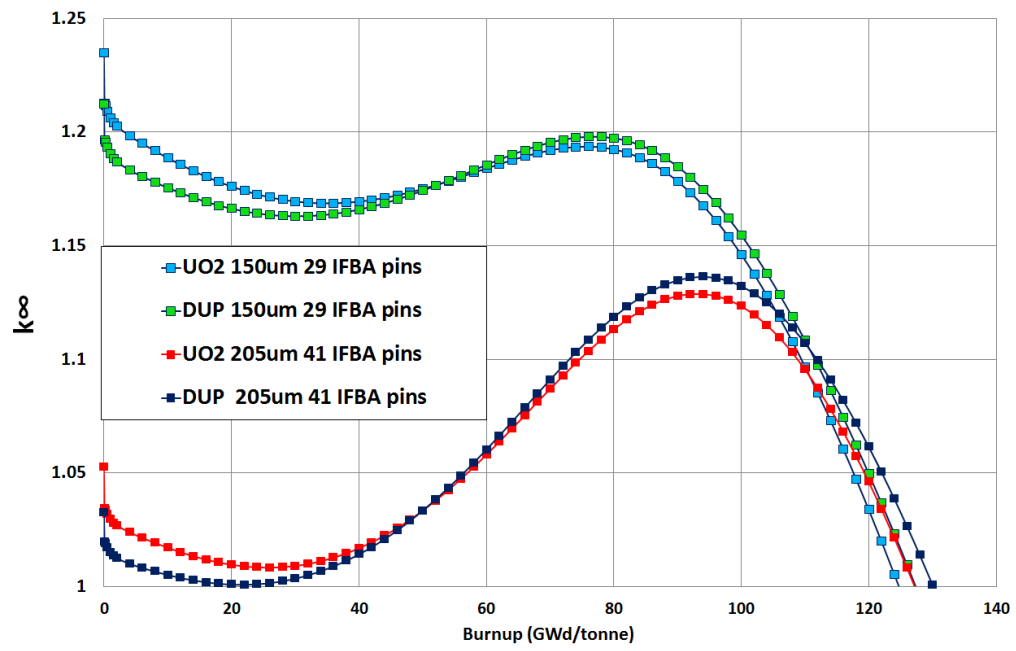

Fig. 8. $k_{\infty}$ vs. burnup for two $\mathrm{ZrB}_{2}$ configurations (29 and 41 pins with $150 \mu \mathrm{m}$ coatings) for duplex, all- $\mathrm{UO}_{2}$ fuels.

\subsection{Final Poison Design for the Mixed Coolant}

It has been well understood for our assembly-level poison study with the mixed coolant that IFBA can effectively act as a BP candidate. However, since the initial reactivity of the candidate fuels with this coolant is significantly higher due to its higher moderating power, the BP design requires further optimization in order to suppress more reactivity and reduce reactivity swing. 


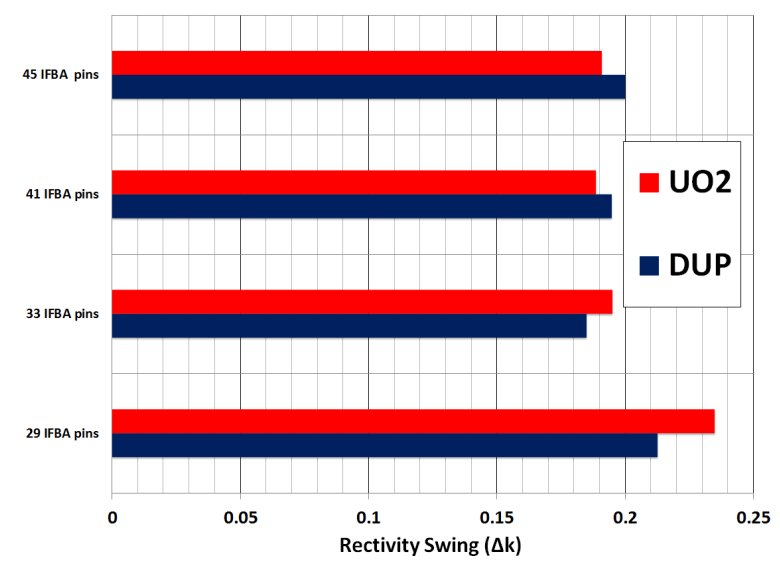

Fig. 9. Reactivity swing for different combinations of fuel/IFBA using $150 \mu \mathrm{m} \mathrm{ZrB}_{2}$.

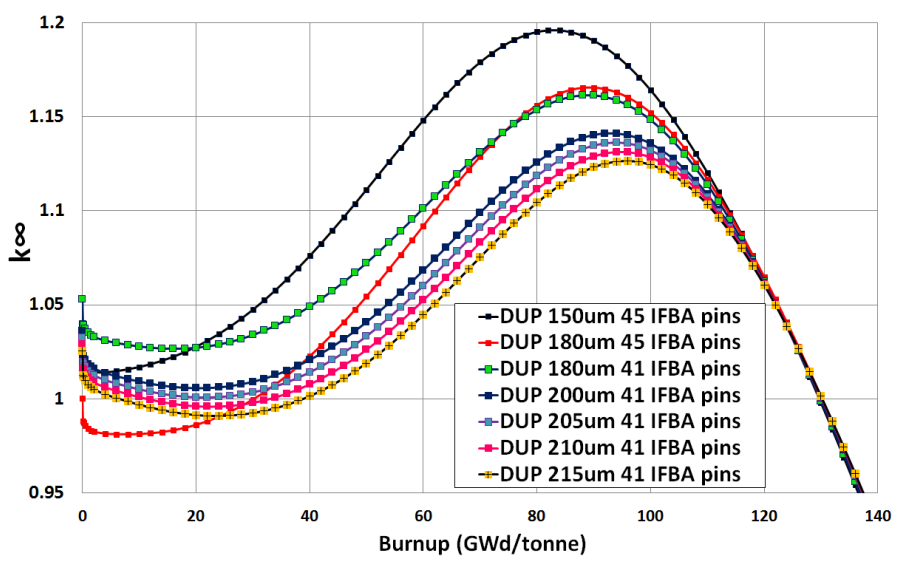

(a)

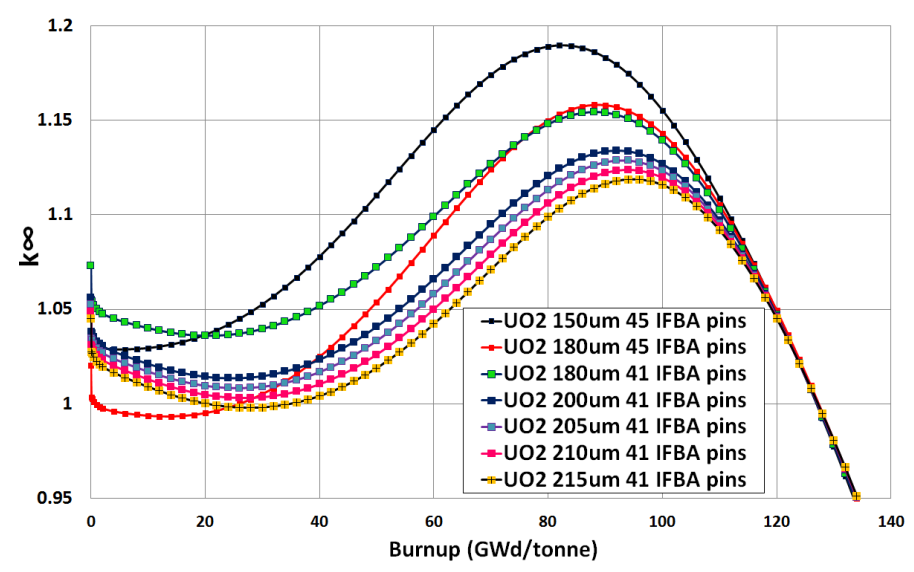

(b)

Fig. 10. Reactivity profile over burnup for different $\mathrm{ZrB}_{2}$ thickness and loadings with the candidate fuels: (a) Duplex; (b) all-UO $\mathrm{UO}_{2}$ 
It has been observed that increasing the BP pins ( $>33$ IFBA pins) for the same (150 $\mu \mathrm{m})$ thickness makes the reactivity swing for duplex fuel worse (Fig. 9). Therefore, we vary the IFBA thickness and number of BP pins in order to achieve the minimum possible BOL $k_{\infty}$ and reactivity swing while maintaining $k_{\infty} \geq 1$ over the burnup cycle. Figs. 10a and 10b show that for both fuels with 41 IFBA pins with $205 \mu \mathrm{m}$ coating satisfy our BP design criteria. $\mathrm{ZrB}_{2}$ IFBA of higher thickness exhibits better BP performance since no less than $\sim 90 \%$ of the incident thermal neutrons are absorbed in a BP thickness of $3 \lambda$ (Alam et al., 2019d). For the candidate fuels, a $205 \mu \mathrm{m}$ thick layer of $\mathrm{ZrB}_{2}$ with 41 pins BP will be used in our control rod design and whole-core analyses.

We can see that the use of mixed coolant requires us to use higher IFBA thickness $(205 \mu \mathrm{m})$ compared to the $\mathrm{H}_{2} \mathrm{O}$ coolant $(150 \mu \mathrm{m})$, consistent with the results obtained in Figs. 6a and $6 \mathrm{~b}$.

\section{Control Rod Design for the Mixed Coolant}

In Section 3 it has been shown that in full power operation the $\left(k_{\infty}, \rho\right)$ for duplex, all- $\mathrm{UO}_{2}$ fuels are less than $(1.136,0.120),(1.128,0.113)$, respectively, for the mixed $\mathrm{D}_{2} \mathrm{O}+\mathrm{H}_{2} \mathrm{O}$ coolant and using 41 IFBA pins coated with a $205 \mu \mathrm{m}$ layer of $\mathrm{ZrB}_{2}$ over the core life of the proposed SMR. In contrast, for the $\mathrm{H}_{2} \mathrm{O}$ coolant, control rod design was established using 25 pins coated in a $150 \mu \mathrm{m}$ layer of $\mathrm{ZrB}_{2}$ poison in our previous study (Alam et al., 2019d). Through-life shutdown margin $\rho_{\mathrm{SM}} \geq 0.14$ is considered in this study according to the previous studies (Demazière, 2002, Otto, 2013). The evaluation of the cores reactivity is needed as a first step in determining the control rod worth. In order to maintain the shutdown margin requirement, it must determine what control materials and how many control rods are necessary.

\subsection{Analysis of Moderator Temperature and Power Conditions Effects on Reactivity of SMR} Assembly

It is seen in Figs. 6a and 6b that in an under-moderated reactor a better-thermalized neutron spectrum can be reached by decreasing the coolant temperature, which leads to 
increase its density, and hence higher reactivity. It is worth mentioning that the undermoderated region of the mixed coolant is somewhat limited by moderator temperature coefficient (MTC) since Fig. 11 shows that increasing the $\mathrm{DH} / \mathrm{HM}>9$ will be detrimental to the MTC. This is due to the fact that neutron absorption for the mixed coolant starts dominating at a lower value of $\mathrm{DH} / \mathrm{HM}\left(k_{\infty}\right.$ peaks at around $\left.\mathrm{DH} / \mathrm{HM} \approx 10\right)$ than that of the $\mathrm{H} / \mathrm{HM}\left(k_{\infty}\right.$ peaks at around $\left.\mathrm{H} / \mathrm{HM} \approx 13\right)$ for the $\mathrm{H}_{2} \mathrm{O}$ coolant (Figs. 6a and $6 \mathrm{~b}$ ) (Alam et al., 2019c). Therefore, in the event of lower fuel/coolant temperature ( $\mathrm{DH} / \mathrm{HM} \approx 5.0)$, the core will experience higher $k_{\infty}$ compared to its normal operating condition. The core must have enough reactivity while determining the control rod worth for this mixed coolant in order to ensure a rapid shutdown even in the event of lower coolant and/or fuel temperatures. In this regard, assembly reactivity is evaluated in three operating conditions while changing the fuel and coolant temperatures (and densities accordingly), as shown in Table 2. It is required to address that the provided temperatures in Table 2 correspond to all fuel assemblies (uniform).

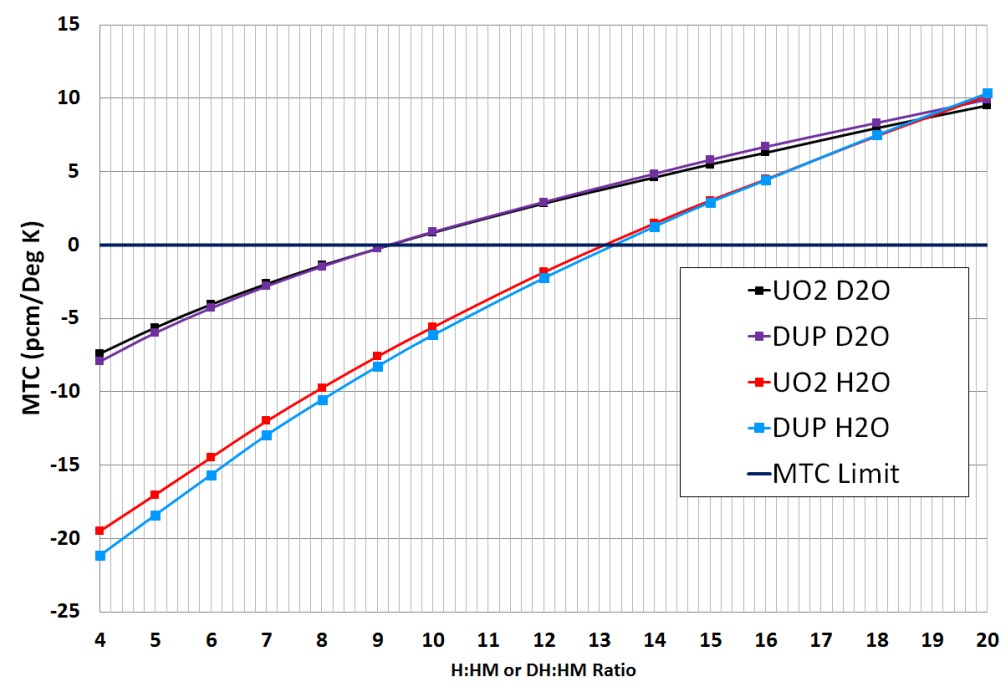

Fig. 11. MTC over H/HM or DH/HM (Alam et al., 2019c).

Fig. 12 shows the assembly reactivity over burnup in three reactor operating conditions (Table 2): hot full power (HFP), hot zero power (HZP) and cold zero power (CZP). As expected, it is clear that the maxim through-life reactivity is seen for the CZP which is $\rho_{\max }($ duplex $)=0.191$ and $\rho_{\max }\left(\mathrm{UO}_{2}\right)=0.183$. Thus, with our desired $\rho_{\mathrm{SM}}$ of 0.140 , the 


\begin{tabular}{|l|c|c|}
\hline Operating conditions & $\begin{array}{c}\text { Fuel } \\
\text { temperature (K) }\end{array}$ & $\begin{array}{c}\text { Coolant/Moderator } \\
\text { temperature (K) }\end{array}$ \\
\hline Hot full power (HFP) & 900 & 580 \\
\hline Hot zero power (HZP) & 580 & 580 \\
\hline Cold zero power (CZP) & 295 & 295 \\
\hline
\end{tabular}

Table 2. Different temperature and power conditions.

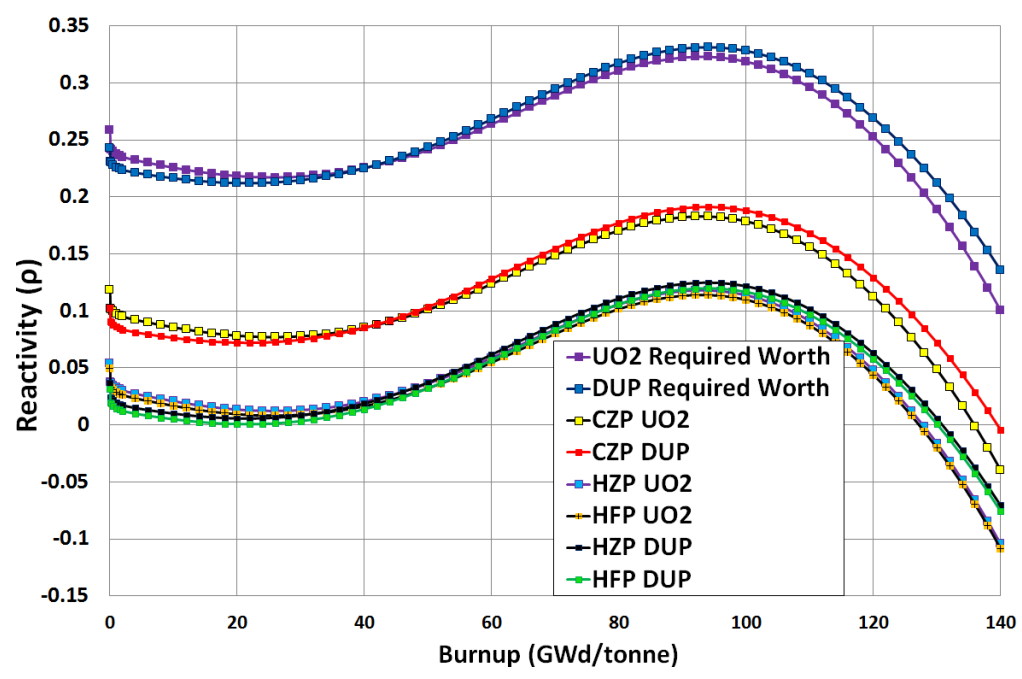

Fig. 12. Assembly reactivity vs. burnup in hot full power, hot zero power and cold zero power. 
required control bank should have a reactivity control worth of $\rho_{\mathrm{CR}}($ duplex $)=(0.191+0.14)=$ 0.331 and $\rho_{\mathrm{CR}}\left(\mathrm{UO}_{2}\right)=(0.183+0.14)=0.323$ for the mixed coolant. For the $\mathrm{H}_{2} \mathrm{O}$ coolant (Alam et al., 2019d), the control bank requires a reactivity worth of $\rho_{C R_{\left(\mathrm{H}_{2} \mathrm{O}\right)}}($ duplex $)=$ 0.304 and $\rho_{C R_{\left(H_{2} O\right)}}\left(\mathrm{UO}_{2}\right)=0.331$. It is worth mentioning that these required worths for the mixed coolant are comparable to those for the $\mathrm{H}_{2} \mathrm{O}$ coolant since we have used higher IFBA thickness and loading to suppress the reactivity to a greater extent.

\subsection{Rod Cluster Control Assembly Worth (RCCA) Evaluation}

For the apposite reasons, energy spectrum mainly influences the choice of reactor control rod materials. Therefore, control rod materials with large CXS (neutron energy range of interest) are more favorable to be employed such as boron and hafnium (Hf). Higher CXS of cadmium $(\mathrm{Cd})$ and gadolinium $(\mathrm{Gd})$ are limited only to the thermal energy range below 1 eV (Shaposhnik et al., 2014). PWRs use $\mathrm{B}_{4} \mathrm{C}$, Hf, Gd and Cd as control rod materials as well as the composition of $(80 \% \mathrm{Ag}, 15 \% \mathrm{In}, 5 \% \mathrm{Cd})$ (AIC) alloy which covers the whole energy spectrum and has a significant CXS in a certain neutron energy range. Therefore in the mixed $\mathrm{D}_{2} \mathrm{O}+\mathrm{H}_{2} \mathrm{O}$ coolant, $\mathrm{B}_{4} \mathrm{C}$, hafnium and $\mathrm{AIC}$ are examined. For the mixed coolant analysis, the number of guide tubes has been increased from 16 (used for $\mathrm{H}_{2} \mathrm{O}$ coolant) to 20 for loading control rods. For each material with the mixed coolant, control bank rod worth $(\Delta \rho)$ of a 20-rod RCCA at full insertion is evaluated at BOL. The results are shown in Table 3 shows the BOL 20-rod worth for the candidate control rod materials.

\begin{tabular}{|l|c|c|}
\hline Material & $\Delta \rho($ Duplex $)$ & $\Delta \rho\left(\mathbf{U O}_{2}\right)$ \\
\hline Hafnium & 0.208 & 0.203 \\
\hline $\mathrm{B}_{4} \mathrm{C}$ & 0.333 & 0.326 \\
\hline $\mathrm{Ag}-\mathrm{In}-\mathrm{Cd}$ & 0.207 & 0.202 \\
\hline
\end{tabular}

Table 3. RCCA (20-rod) worth for for the mixed coolant.

Table 3 shows that RCCA worth for the mixed coolant is $\sim 3 \%$ greater in the duplex fuel for all control materials than that of the $\mathrm{UO}_{2}$ fuel, consistent with the findings for $\mathrm{H}_{2} \mathrm{O}$ coolant (Alam et al., 2019d). 
Now, Table 3 shows that the worths of our control bank, $\Delta \rho($ duplex $)=0.333$ and $\Delta \rho\left(\mathrm{UO}_{2}\right)=0.326$, are almost equal to the required worths identified in Sect. 4.1: $\rho_{\mathrm{CR}}($ duplex $)=$ 0.331 and $\rho_{\mathrm{CR}}\left(\mathrm{UO}_{2}\right)=0.323$. We can see that a 20-rod control bank gives the required shutdown margins for both candidate fuels. It is important to note that the use of mixed coolant necessitates a higher control rod requirement (20-rod RCCA) than for the $\mathrm{H}_{2} \mathrm{O}$ coolant (16-rod RCCA).

\section{Whole-Core Feasibility of the Mixed Coolant}

It is now important to observe the whole-core neutronic feasibility of the mixed coolant. As addressed, the scope of this whole-core neutronic feasibility is limited to evaluate and understand the core life while observing reactivity feedback values over the core life. The analyses of power peaking factors, axial offset and shutdown margin will be reported in the future study after performing core design optimization studies.

In section 3 and section 4 , we developed an assembly design for the mixed coolant. The 112-assembly whole-core was modeled using PANTHER in a pattern of three radial zones (see Fig. 13a). In addition, 3 banks (A, B and C) for power maneuvering and 3 other banks (SA, SB and SC) for shutdown operation are used, as shown in Fig. 13b.

It has been confirmed in our previous studies (Alam et al., 2015) that burnable poison zoning (BPZ) performs better than fissile zoning (FZ) in terms of controlling through-life reactivity swing and power peaking for the reference core (Alam et al., 2019g). Therefore, we have investigated BPZ in this feasibility analysis of the mixed coolant core. Since the use of mixed coolant increases the core reactivity, $\mathrm{BP}$ arrangement is employed with higher poison loading to control the radial form factor $(\mathrm{RFF})$ while obtaining the highest achievable core life. The BPZ scheme considered used 41, 33 and 25 IFBA pins in zones A, B and C, respectively while considering reference ${ }^{235} \mathrm{U}$ content.

It can be seen in Fig. 14 that both the candidate fuels utilizing mixed coolant can successfully obtain the core lifetime of $\sim 21.5$ years for both the fuel configurations. The use of the mixed coolant facilitates an additional $\sim 6$ years core life over that for the $\mathrm{H}_{2} \mathrm{O}$ coolant, which is a $\sim 40 \%$ increase in core life due to the use of the mixed coolant. Duplex core 


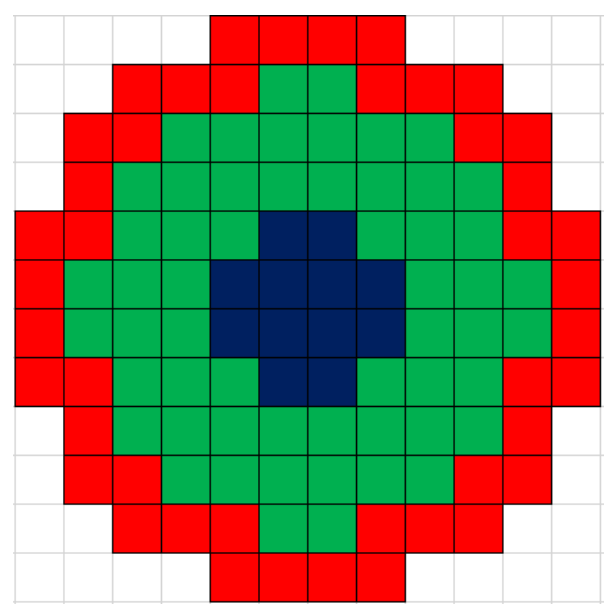

(a)

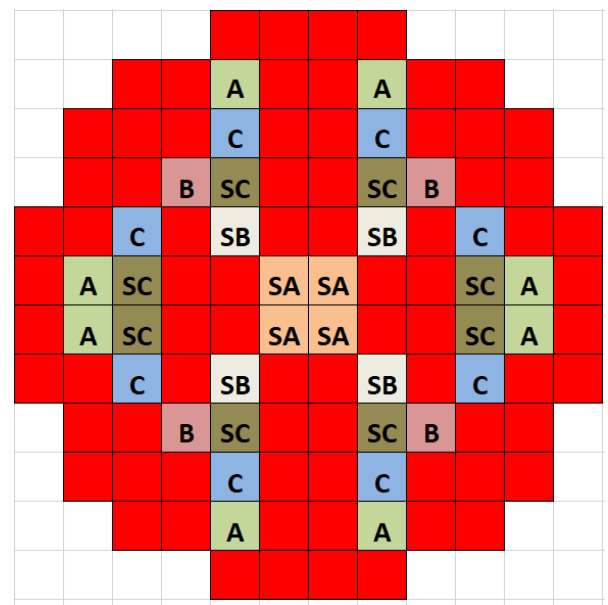

(b)

Fig. 13. (a)112-assembly radial zoning pattern: blue $=\mathrm{A}$ (central zone), green $=\mathrm{B}$ (inner zone), red $=\mathrm{C}$ (outer zone); (b) Control rod bank positions. 
with the mixed coolant, in fact, exhibits $\sim 2 \%$ longer core life compared to the all- $\mathrm{UO}_{2}$ core (consistent with findings with the $\mathrm{H}_{2} \mathrm{O}$ coolant) because of the higher thermal fertile-to-fissile thermal absorption ratio (Fig. 15) of the duplex core (Jagannathan et al., 2008). In addition, it can be also observed in Fig. 14 that BPZ cores with mixed coolant exhibit an additional $3000 \mathrm{pcm}$ reactivity swings reactivity at the expense of $\sim 40 \%$ increase in core lifetime.

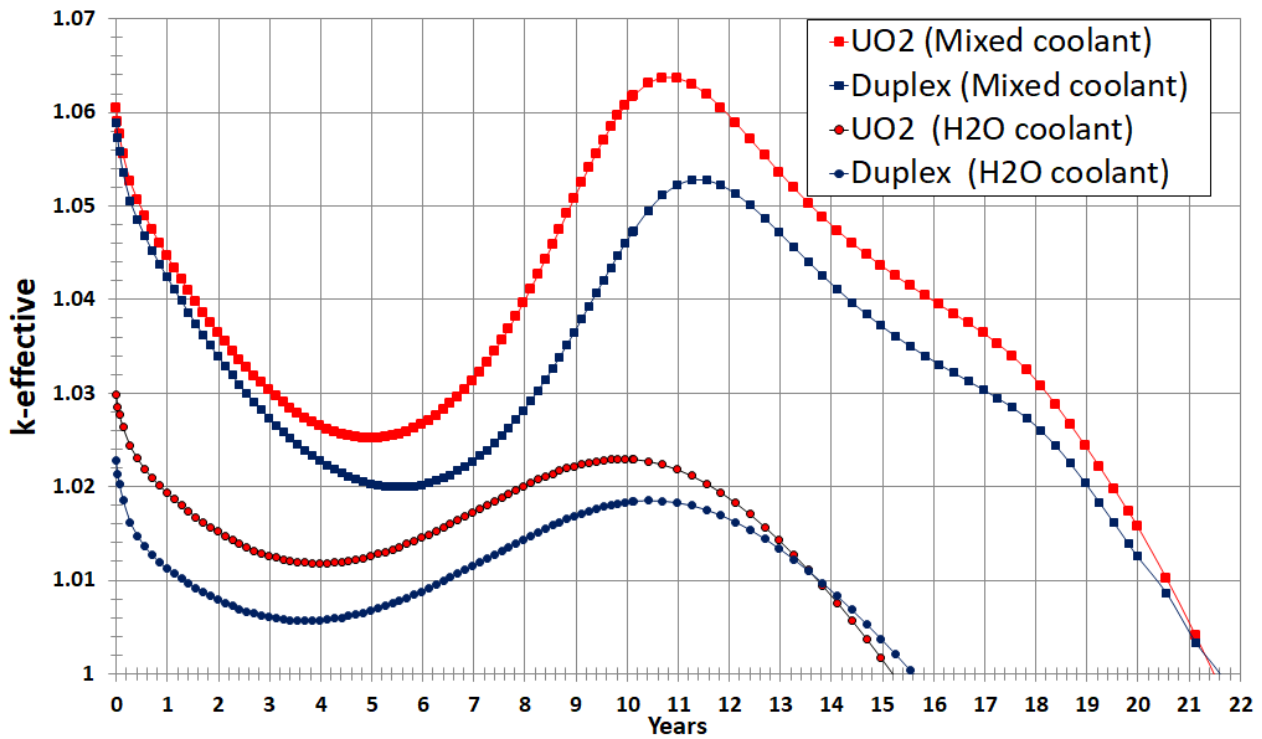

Fig. 14. Time behavior of $k_{\text {eff }}$ for the radial-zoning core loading patterns with $\mathrm{H}_{2} \mathrm{O}$ and mixed coolants. fuel; more negative reactivity coefficient is resulted in duplex compared to the all- $\mathrm{UO}_{2}$ cores.

Furthermore, as the mixed coolant temperature increases, more neutrons get absorb in the ${ }^{232} \mathrm{Th}$ resonances leads to more negative MTC values in duplex than the all- $\mathrm{UO}_{2}$ cores, as shown in Fig. 17. At the BOL, the MTC values are higher for both fuels and become more negative with the burnup/depletion due to the increased variety of actinides and fission products (FPs) present. As the burnup progresses (up to $\sim 20$ years), in the $\mathrm{UO}_{2}$ fuel, the more plutonium (particularly ${ }^{239} \mathrm{Pu}$ ) is generated than that of the duplex fuel, leads to become the MTC slightly more negative in the all- $\mathrm{UO}_{2}$ compare to the duplex cores. Since ${ }^{239} \mathrm{Pu}$ exhibits strong resonance at $0.5 \mathrm{eV}, \mathrm{UO}_{2}$ cores exhibit marginally more negative MTC 


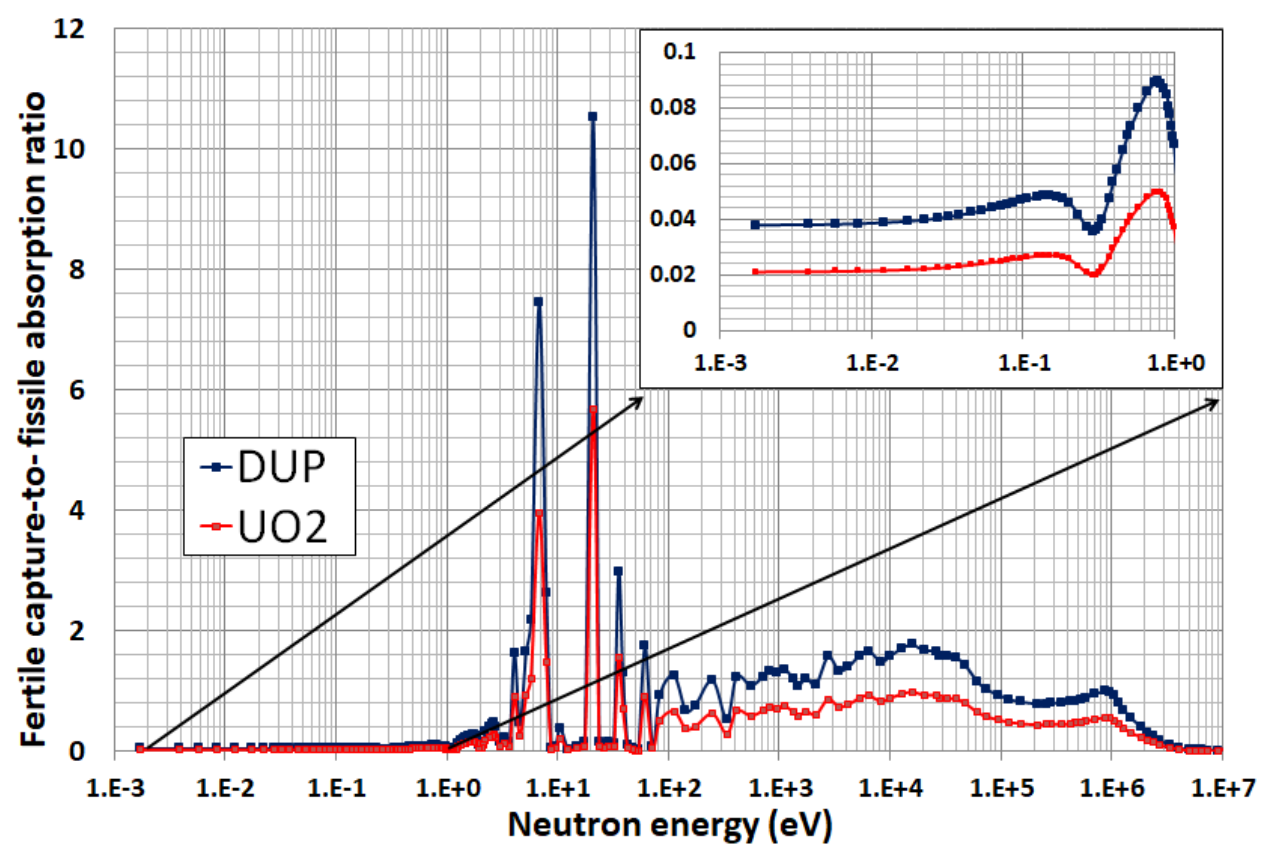

Fig. 15. Fertile-to-fissile absorption ratios at BOL in mixed coolant.

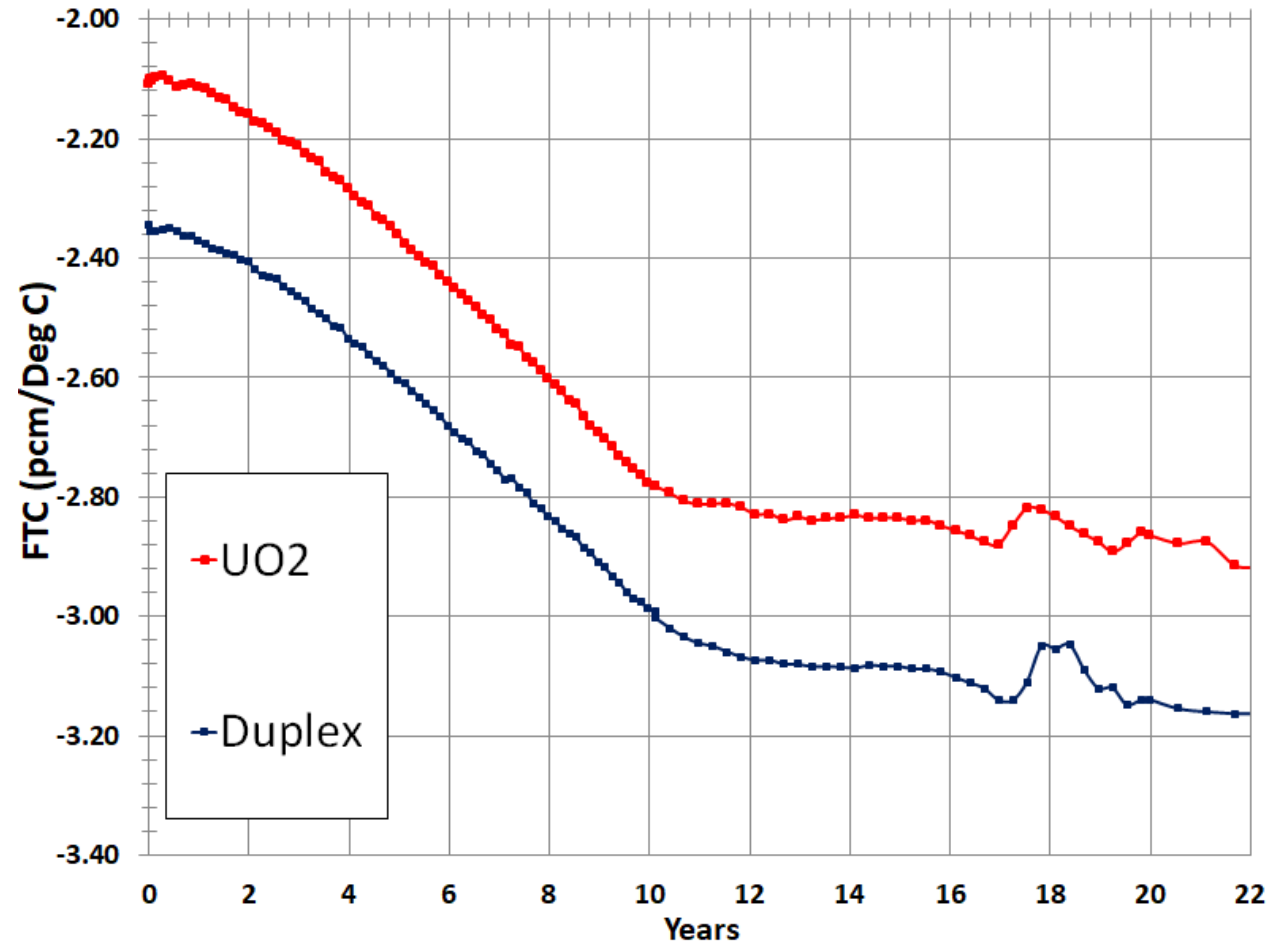

Fig. 16. Time behavior of FTC for the radial-zoning core loading patterns. 

$2019 \mathrm{~g})$.

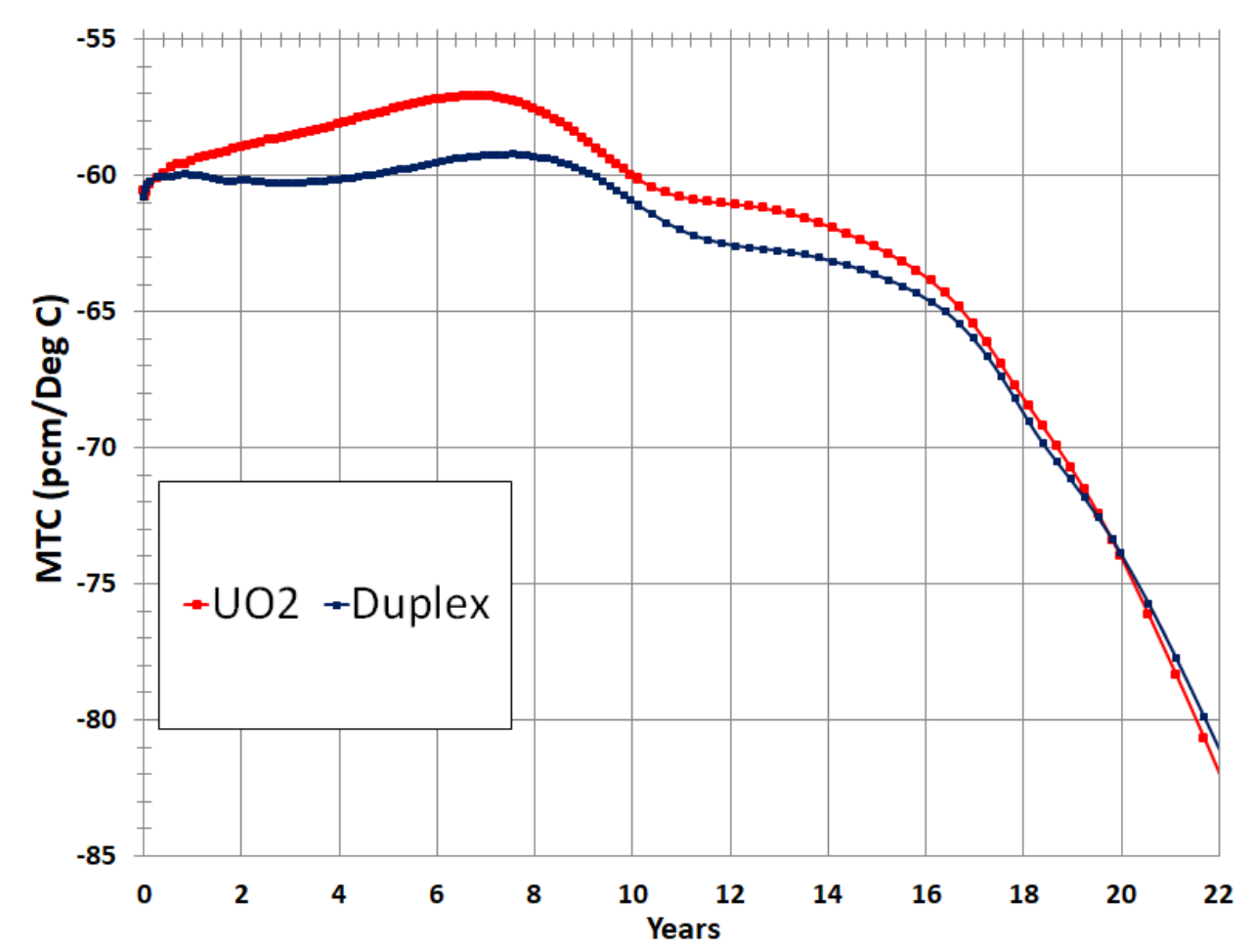

Fig. 17. Time behavior of MTC for the radial-zoning core loading patterns.

later in life (Alam et al., 2019g). It is noteworthy that the FTC and MTC behaviors of the candidate fuels with the mixed coolant are similar to those for the $\mathrm{H}_{2} \mathrm{O}$ coolant (Alam et al.,

In addition, Fig. 18 shows that the Doppler power coefficient (DPC) is negative through the core lifetime. Duplex has more negative DPC values compared to the $\mathrm{UO}_{2}$ cores, which implies a lower power defect compared for $\mathrm{UO}_{2}$ core, which is beneficial to shutdown margin and provides reduced reactivity reserve required for load following operations. However, reactivity feedback coefficients would not be an issue for the mixed coolant.

\section{Conclusions}

This paper presented the neutronic feasibility of a soluble-boron-free civil marine SMR core with the mixed coolant utilizing thorium-based micro-heterogeneous fuel. The main findings obtained from this study are as follows: 


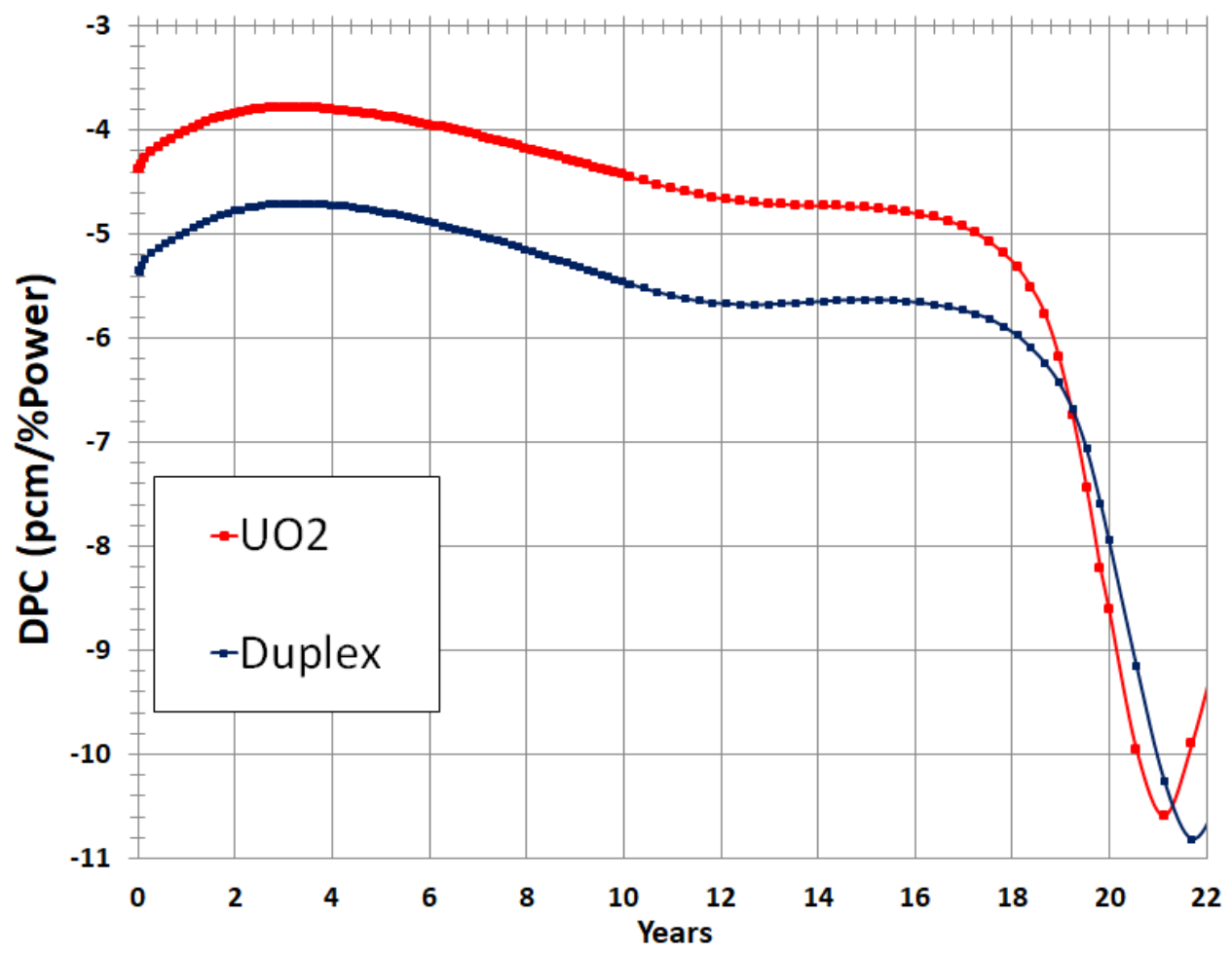

Fig. 18. Time behavior of DPC for the radial-zoning core loading patterns.

- The use of the mixed coolant contributes to $\sim 21.5$ years core life, which is a $\sim 40 \%$ increase in core life compared to $\mathrm{H}_{2} \mathrm{O}$ coolant while using the same fuel candidates and fissile enrichment. The mixed coolant provides excellent core lifetimes comparable to those of HEU military naval vessels ( $\sim 25$ years vs. $\sim 22$ years) at the expense of higher through-life reactivity swings of $\sim 6,000$ pcm, whereas $\mathrm{H}_{2} \mathrm{O}$ coolant exhibits a through-life reactivity swing of $\sim 4,000 \mathrm{pcm}$.

- Duplex core with the mixed coolant, in fact, exhibits $\sim 2 \%$ longer core life compared to the $\mathrm{UO}_{2}$ core, consistent with findings with the $\mathrm{H}_{2} \mathrm{O}$ coolant) because of the higher fertile-to-fissile thermal absorption ratio.

- The duplex fuel is capable of reducing the requirements of burnable poison for the $\mathrm{D}_{2} \mathrm{O}+\mathrm{H}_{2} \mathrm{O}$ coolant due to its lower through-life reactivity swing.

- Duplex core exhibits higher control rod worth compared to the all- $\mathrm{UO}_{2}$ fuel with the 
$\mathrm{D}_{2} \mathrm{O}+\mathrm{H}_{2} \mathrm{O}$ coolant. However, the use of the mixed coolant necessitates higher BP and control rod requirements than the $\mathrm{H}_{2} \mathrm{O}$ coolant.

- The reactivity swing results for the mixed coolant are mixed depending on the thickness and loading. The duplex fuel experiences lower swings over burnup than that of the $\mathrm{UO}_{2}$ fuel for lower BP loadings (less than 37 IFBA pins). Things are different with higher BP loadings (greater than 37 IFBA pins), where the duplex fuel exhibits worse reactivity swing performance than $\mathrm{UO}_{2}$ due to the delay in the build-up of ${ }^{233} \mathrm{U}$ resulting from the very high-thickness $\mathrm{ZrB}_{2}$ coating.

- Generally, thorium-based micro-heterogenous duplex core exhibits considerably more negative reactivity coefficient (FTC and MTC) values than that of the all- $\mathrm{UO}_{2}$ core.

The following objectives/aspects will be focused on future works:

- To use of the mixed coolant contributes to ultra-long life at the expense of higher through-life reactivity swings of $\sim 6,000$ pcm than that of the $\mathrm{H}_{2} \mathrm{O}$ coolant. Future studies will consider the core design optimization studies for reducing the reactivity swing while meeting all the neutronic safety requirements.

- The scope of this paper was limited to evaluate and understand the core life while observing reactivity feedback values over the core life. Future studies will consider the detailed analyses of the power peaking factors, axial offset and shutdown margin after performing core design optimization studies.

- High power density SMR cores (Alam et al., 2019f) experience a core life penalty due to the associated reduction in fuel mass. Since this mixed coolant exhibits promise in offering longer core lifetime than the $\mathrm{H}_{2} \mathrm{O}$ coolant (Alam et al., 2019c), it has the potential to compensate this core life penalty. Therefore, future study will conduct the core design studies of HPD SMR cores with the mixed coolant.

- Future work will focus on fuel performance analyses in terms of fission gas release, pellet clad interaction and oxide thickness. 
- Xenon transient and xenon-induced oscillations will also be investigated in the future.

- Nuclear data uncertainties for the mixed coolant will also be observed.

- Licensing/manufacturing aspect of the duplex fuel will also be an interesting point to explore.

\section{Additional information}

(1) Some portions of the article are published in the Ph.D. thesis and a conference paper of the first author. (2) The first author was a Doctoral Researcher at the University of Cambridge where this study has been conducted using the local repository and in-house licensed reactor physics codes: WIMS and PANTHER. This is not the current affiliation of the first author. Since this work has been conducted at the first author's Ph.D. institution (University of Cambridge) using the licensed codes and local repository, it is included as the affiliation to showcase where this work has been originally performed.

\section{References}

Alam, S.B., 2018. The Design of Reactor Cores for Civil Nuclear Marine Propulsion. Ph.D. thesis. University of Cambridge. Cambridge, UK.

Alam, S.B., Almutairi, B., Ridwan, T., Kumar, D., Goodwin, C., Atkinson, K.D., Parks, G.T., 2019a. Neutronic investigation of alternative \& composite burnable poisons for the soluble-boron-free and long life civil SMR cores. Accepted in Scientific Reports .

Alam, S.B., Goodwin, C.S., Parks, G.T., 2019b. Assembly-level analyses of accident-tolerant cladding concepts for a long-life civil marine SMR core using micro-heterogeneous duplex fuel. Prog Nucl Energ $111,24-41$.

Alam, S.B., Goodwin, C.S., Parks, G.T., 2019c. Parametric neutronics analyses of lattice geometry and coolant candidates for a soluble-boron-free civil marine SMR core using micro-heterogeneous duplex fuel. Annals of Nuclear Energy 129, 1-12.

Alam, S.B., Kumar, D., Almutairi, B., Bhowmik, P.K., Goodwin, C., Parks, G.T., 2019d. Small modular reactor core design for civil marine propulsion using micro-heterogeneous duplex fuel. Part I: Assembly-level analysis. Nucl Eng Des. 346, 157-175. 
Alam, S.B., Kumar, D., Almutairi, B., Ridwan, T., Goodwin, C., Parks, G.T., 2019e. Lattice benchmarking of deterministic, Monte Carlo and hybrid Monte Carlo reactor physics codes for the soluble-boron-free SMR cores. Nucl Eng Des. .

Alam, S.B., Lindley, B.A., Parks, G.T., 2015. Feasibility study of the design of homogeneously mixed thorium-uranium oxide and all-uranium fueled reactor cores for civil nuclear marine propulsion, in: Proc. ICAPP 2015, Nice, France. pp. 1918-1927.

Alam, S.B., de Oliveira, R.G., Goodwin, C.S., Parks, G.T., 2019f. Coupled neutronic/thermal-hydraulic hot channel analysis of high power density civil marine SMR cores. Annals of Nuclear Energy 127, 400-411.

Alam, S.B., Ridwan, T., Kumar, D., Almutairi, B., Bhowmik, P.K., Goodwin, C., Parks, G.T., 2019g. Small modular reactor core design for civil marine propulsion using micro-heterogeneous duplex fuel. Part II: Whole-core analysis. Nucl Eng Des. 346, 176-191.

Demazière, C., 2002. Reactor physics calculations on MOX fuel in BWRs, in: Proc. 7th Information Exchange Meeting on Actinide and Fission Product Partitioning and Transmutation, Jeju, Korea. pp. 14-16.

Engelder, T.C., 1961. Spectral Shift Control Reactor Basic Physics Program: Critical Experiments on Lattices Moderated by $\mathrm{D}_{2} \mathrm{O}-\mathrm{H}_{2} \mathrm{O}$ Mixtures. volume 1231. Office of Technical Services.

Fan, H., 2012. The Conceptual Design of a Marine Propulsion Reactor Core. Master's thesis. Department of Engineering, University of Cambridge. Cambridge, UK.

Hass, B., 2014. Strategies for the success of nuclear powered commercial shipping, in: Connecticut Maritime Association.

Hirdaris, S., Cheng, Y., Shallcross, P., Bonafoux, J., Carlson, D., Prince, B., Sarris, G., 2014. Considerations on the potential use of nuclear small modular reactor (SMR) technology for merchant marine propulsion. Ocean Eng. 79, 101-130.

Hutt, P., 1992. Overview Functional Specification of PANTHER: A Comprehensive Thermal Reactor Code for Use in Design, Assessment and Operation. PANTHER/FSPEC/OVERVIEW 2.0, Nuclear Electric plc, Barnwood, UK.

Ippolito, T.D., 1990. Effects of variation of uranium enrichment on nuclear submarine reactor design. Master's thesis. Massachusetts Institute of Technology.

Jagannathan, V., Pal, U., Karthikeyan, R., Raj, D., Srivastava, A., Khan, S.A., 2008. Reactor physics ideas to design novel reactors with faster fissile growth. Energy Convers. Manage. 49, 2032-2046.

Kramer, A., 1962. Nuclear Propulsion for Merchant Ships. US Atomic Energy Commission, Washington, DC. MacDonald, P., Lee, C., 2004. Use of thoria-urania fuels in PWRs: A general review of a NERI project to assess feasible core designs, economics, fabrication methods, in-pile thermal/mechanical behavior, and waste form characteristics. Nucl. Technol. 147, 1-7.

Nagy, M., Aly, M., Gaber, F., Dorrah, M., 2014. Neutron absorption profile in a reactor moderated by 
different mixtures of light and heavy waters. Annals of Nuclear Energy 72, 487-496.

Namikawa, S., Mærli, M., Hoffmann, P., Brodin, E., 2011. Nuclear powered ships - findings from a feasibility study, in: Proc. 19th Int. Conf. Nuclear Engineering (ICONE19), Chiba, Japan.

Newton, T., Hosking, G., Hutton, L., Powney, D., Turland, B., Shuttleworth, E., 2008. Developments within WIMS10, in: Proc. PHYSOR 2008, Interlaken, Switzerland.

Otto, R.T., 2013. Core Optimization in a Thorium-based Civil Marine Propulsion Reactor. Master's thesis. Department of Engineering, University of Cambridge.

Ragheb, M., 2012. Nuclear marine propulsion. University of Illinois at Urbana-Champaign .

Shaposhnik, Y., Shwageraus, E., Elias, E., 2014. Shutdown margin for high conversion BWRs operating in Th-U233 fuel cycle. Nucl. Eng. Des. 276, 162-177.

Sun, H., 2014. Marine Reactor Core Physics Study. Master's thesis. Department of Engineering, University of Cambridge. Cambridge, UK.

Tochihara, H., Komano, Y., Ishida, M., Narukawa, K., Umeno, M., 1998. Nuclear design for mixed moderator PWR. Progress in Nuclear Energy 32, 533-537.

Xu, Z., 2003. Design strategies for optimizing high burnup fuel in Pressurized Water Reactors. Ph.D. thesis. Massachusetts Institute of Technology. Cambridge, MA.

$\mathrm{Xu}, \mathrm{Z}$., Driscoll, M., 1997. Neutron spectrum effects on burnup, reactivity, and isotopics in $\mathrm{UO}_{2} / \mathrm{H}_{2} \mathrm{O}$ lattices. Nucl. Sci. Eng. 141, 175-189.

Zhang, J., 2013. Commercial Nuclear Marine Reactor Physics Design for Uranium Fuel. Master's thesis. Department of Engineering, University of Cambridge. Cambridge, UK.

Zhao, X., 2001. Micro-heterogeneous Thorium Based Fuel Concepts for Pressurized Water Reactors. Ph.D. thesis. Massachusetts Institute of Technology. Cambridge, MA. 